\title{
$\frac{322}{15-66 \mathrm{feg}}$
}

AEC Research and Development Report

\section{THE MECHANICAL PROPERTIES OF}

\section{DILUTE URANIUM ALLOYS AT ELEVATED TEMPERATURES}

\section{August 1, 1966}

LEGAL NOTICE Neither the United an account of Government sponsored work, This report was prepared as an accoun person acting on behalf of the Com with respect to the accuState nor the Commission, nor any perstion, expressed or implied, wh repert, or that the use A racy, completeness, or usefulness of the in process disclosed in this teport may not in of any information, appar privately owned rights; or with respect to the use of, or for damas report.

method, or process disclosed in tission" includes any emB. Any information. apparates meter that

As used in the above. "persion, or employee of such controch contractor prepares. As contractor of the Commision, or employee of sis employment or contrac ployee or coloyee or contractor of the Comy information pursuan disseminates, or provides access to, with such contractor.

with the Com

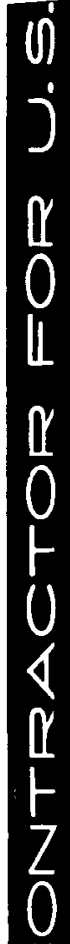

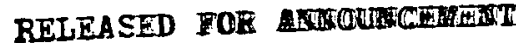

IN NUCLEAR SCIENCE AESTRACTS

\section{WELDON SPRING PLANT}

\author{
MALLINOKFODT CHEMIOAL MORKS \\ URANIUM GIVISION \\ Gontract No. W-14-108-Eng-
}




\section{DISCLAIMER}

This report was prepared as an account of work sponsored by an agency of the United States Government. Neither the United States Government nor any agency Thereof, nor any of their employees, makes any warranty, express or implied, or assumes any legal liability or responsibility for the accuracy, completeness, or usefulness of any information, apparatus, product, or process disclosed, or represents that its use would not infringe privately owned rights. Reference herein to any specific commercial product, process, or service by trade name, trademark, manufacturer, or otherwise does not necessarily constitute or imply its endorsement, recommendation, or favoring by the United States Government or any agency thereof. The views and opinions of authors expressed herein do not necessarily state or reflect those of the United States Government or any agency thereof. 


\section{DISCLAIMER}

Portions of this document may be illegible in electronic image products. Images are produced from the best available original document. 


\section{LEGAL NOTICE}

This report was prepared as an account of Government sponsored work. Neither the United States, nor the Commission, nor any person acting on behalf of the Commission:

A. Makes any warranty or representation, expressed or implied, with respect to the accuracy, completeness, or usefulness of the information contained in this report, or that the use of any information, apparatus, method, or process disclosed in this report may not infringe privately owned rights; or

B. Assumes any liabilities with respect to the use of, or for damages resulting from the use of ony information, apparatus, method, or process disclosed in this report.

As used in the above, "person octing on behalf of the Commission" includes any employee or controctor of the Commission, or employee of such contractor, to the extent that such employee or contractor of the Commission, or employee of such contractor prepares, disseminates, or provides access to, any information pursuant to his employment or contract with the Commission, or his employment with such contractor.

Printed in USA. Price $\$ 3.00$. Available from the Clearinghouse for Federal Scientific and Technical Information, National Bureau of Standards, U. S. Department of Commerce, Springfield, Virginia 
MCW-1505

$$
\begin{gathered}
\text { UC-25, Metals, Ceramics } \\
\text { and Materials } \\
\text { (TID-4500, 48th Edition) }
\end{gathered}
$$

\title{
$\cos 2 \mathrm{2}+\mathrm{Cos}$
}

F. . $\$ 3.00 ; \mathrm{mN} .75$

TOPICAL REPORT

THE MECHANICAL PROPERTIES OF

DILUTE URANIUM ALLOYS AT ELEVATED TEMPERATURES

by

M. F. Nolan

August 1, 1966

\author{
Mallinckrodt Chemical Works \\ Uranium Division \\ Weldon Spring, Missour1
}




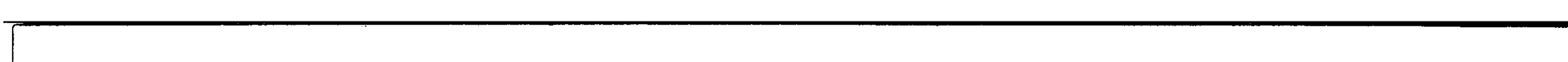

•

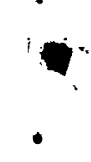

.

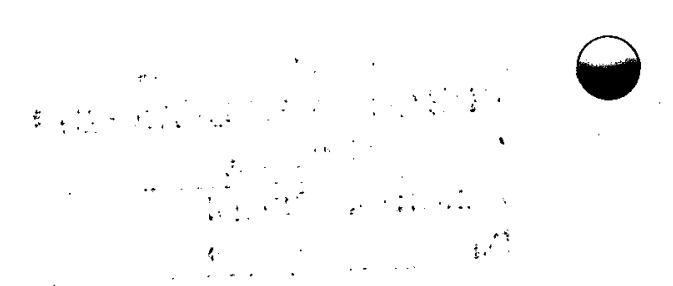




\section{DISTRIBUTION}

Number of Copies

Internal

12

External in accordance with TID-4500, 48th Edition Category UC-25, Metals, Ceramics, and Materials

Battelle-Northwest

J. E. Minor

R. S. Kemper

F. W. Albaugh

S. H. Bush

J. J. Cadwe11

G. A. Last

Cincinnati Area Office U.S.A.E.C.

C. L. $\operatorname{Kar} 1$

W. T. Warner

Division of Production, Washington U.S.A.E.C.

F. P. Baranowski

1

F. R. Dowling

W. Devine, Jr.

Douglas Untted Nuclear, Richland

W. M. Mathis

J. T. Stringer

C. D. Harrington

C. W. Kuhlman

Dow Chemical Co., Rocky F1ats

L. A. Matheson

du Pont Company, Aiken

T. C. Evans

R. T. Huntoon

W. R. McDonnel1

du Pont Company, Wilmington

W. B. DeLong

J. W. Croach 


\section{General Electric Company, Richland}

M. Lewis

J. W. Nickolaus

A. E. Guay

T. D. Naylor

National Lead Company of Ohio

S. Marshall.

C. E. Pokon:

C. E. Bussert

Oak Ridge Operations Office

S. R. Sapirie

J. W. Ruch

B. M. Robinson

1

R. E. Wedemeyer

Richland Operations office

A. T. Gifford

P. M. Midkiff

O. W. Rathbun

St. Louis Area Office

F. H. Belcher

Savannah River Operations office

H. L. Kilburn

I. A. Hobbs

N. J. Donahue 
THE MECHANICAL PROPERTIES OF

DILUTE URANIUM ALLOYS AT ELEVATED TEMPERATURES

by

M. F. Nolan

\begin{abstract}
High temperature tensile tests and prolonged hot hardness tests of uranium alloys were undertaken for possible correlation with in-reactor behavior. Tensile test techniques are discussed for one alloy tested at $25^{\circ} \mathrm{C}$ and between $100^{\circ}$ and $600^{\circ} \mathrm{C}$ at $100^{\circ}$ intervals. The mechanism of flow and fracture is discussed in terms of temperature structure, strain and strain rate. Activation energy values for plastic flow are presented.

Hot hardness tests at $400^{\circ} \mathrm{C}$ under a 600 pound load applied for 22 hours are described for both springloaded and level-loaded equipment. The data indicated that the diameter of indentation decreased as the alloy content of the uranium increased. The resistant to Indentation, however, appeared to be a function of the degree of solid solution hardening and not of the total alloy content. A sensitive response to thermal history therefore seemed likely. A correlation with resistant to in-reactor swelling was not obtained.
\end{abstract}


$\bullet$ 
THE MECHANICAL PROPERTIES OF

DILUTE URANIUM ALLOYS AT ELEVATED TEMPERATURES

by

M. F. Nolan ${ }^{*}$

\section{INTRODUCTION}

One of the major limitations of uranium metal as a reactor fuel is swelling during irradiation. A recent study was made at the Savannah River Laboratory of swelling in natural uranium irradiated to burnups of from 0.05 to 0.77 atomic percent in the temperature range of from $130^{\circ} \mathrm{C}$ to $550^{\circ} \mathrm{C}$. ${ }^{1}$ Large volume increases were encountered at temperatures from 370 to $500^{\circ} \mathrm{C}$ and at atomic burnups of greater than 0.2 percent. Precipitation of fission gas bubbles accounted for only $0.5 \%$ of the volume increases. Cavities 10 to 200 microns in length were responsible for the remainder of the swelling.

It was postulated that the mechanism responsible for this cavitation is simflar to the formation of voids due to grain boundary sliding during elevated temperature creep tests. This phenomenon takes place between the recovery and recrystallization temperatures of a metal when deformation by slip is taking place throughout the grains. If shearing takes place adjacent to grain, subgrains, and twin boundaries blocked by suitable obstacles such as a quadruple point or a jog in the boundary, continued shearing builds up hydrostatic pressure. If the pressure exceeds the cohesive strength of the material, a cavity is formed and further deformation along the boundary will cause it to grow.

Under Irradiation, the necessary stress for cavity formation is built up through anisotropic growth of the crystallites. Similar cavities have been observed in thermal cycling experiments of uranium where the stress was provided by thermal anisotropic growth.

Dilute alloy additions to the natural uranium have been found to increase the resistance of the metal to cavitational swelling. ${ }^{3}$ It was the purpose of work conducted at Weldon Spring to develop equipment and procedures to evaluate the mechanical properties of dilute uranium alloys at elevated temperatures in order to look for possible correlations with their irradiation behavior. Although cavitation swelling under irradiation has been related to behavior observed during creep tests, the expense and time necessary for such tests are serious investments. Since several investigators have found correlations between creep properties and shorter term elevated temperature tensile and hardness tests in other materials, 4,5 these latter tests were chosen to evaluate the dilute uranium alloys.

\footnotetext{
*Now associated with Diversified Metals Corporation, 123 Byassee Drive,
} Hazelwood, Missouri 63042. 
ELEVATED TEMPERATURE TENSILE TESTS

Introduction

Many investigations of the elevated temperature tensile properties of uranium have been made. Investigators have found the properties to be influenced by additive levels and precipitate distribution, grain size and shape, temperature, strain rate, and previous thermal and fabrication history. In order truly to characterize the mechanical properties of a material, all of these factors must be taken into consideration. The choice of testing equipment and procedures was undertaken with these factors in mind.

\section{Equipment}

The equipment developed for elevated temperature tensile testing may be divided into three categories according to the function it serves: (1) control of environment; (2) detection of load, deformation and temperature; and (3) recording of load and elongation.

The environment system includes the tensile tester and the furnace with its associated vacuum and temperature control equipment. The tensile tester was a hydraulically actuated Baldwin Tote Emery 60,000 pound Universal testing machine. A Satec Model RA1800 vacuum furnace with an NRC 2-Inch diffusion pump was attached to one of the columns on the machine, as is shown in Figure 1, and could be swung out of the way when not in use. It was capable of sustained operation at $1800^{\circ} \mathrm{F}$ with a vacuum of $10^{-4}$ torr.

Figure 2 shows the cabinet containing the vacuum and temperature controls. The vacuum controls utilized electric solenoid valves, thermocouple and ion gages, and an NRC Protectovac unit which isolated the diffusion pump should the pressure in the furnace suddenly rise.

Temperature control was accomplished with a Honeywell system consisting of an Electronik 18 recorder and Electr-0-Pulse 18 controller in conjunction with a variable transformer. The sensing thermocouple was of Chromel Alumel wire positioned on the vacuum retort at the center of the furnace.

The center portion of the furnace windings was equipped with movable taps to increase or decrease power in the heating zone. A zone control powerstat allowed transfer of power from one control zone to another within the heating zone to equalize the temperature profile along the sample. Pull rods of Inconel 750 were used in the hot zone of the furnace. Two sets were available, one for one-quarter-inch and the other for one-half-inch diameter shoulderedend samples.

Water- or air-cooled pull rod extensions passed through special vacuum seals at each end of the furnace. These seals consisted of two wiping-type glands enclosed in an evacuated case and preloaded. This allowed friction-free movement of the pull rod extensions without a loss of vacuum. A test of the atmospheric pressure loading of the pull rod extensions when the furnace was under vacuum revealed it to be negligible. 
The vacuum seals for the pull rod extensions were mounted in bellows assemblies. This prevented the furnace from disturbing the uniaxial alignment of the sample train. The extensions were threaded into spherically seated studs in the upper and lower crossheads of the testing machine.

During testing, the furnace was suspended between the moving upper crosshead and a stationary support by a pulley so that the furnace would move half the distance of increased separation between the upper and lower crossheads. This kept the sample centered in the hot zone of the furnace.

The detection equipment may be divided into three systems: load, extension, and temperature. The load detection system was part of the testing machine. Its major component was an Emery hydraulic weighing capsule which activated the load indicator on the control console. The extension of the sample during testing was measured by a Wiedemann high-temperature, multi-range extensometer Mode1 IS -5043 .

Extension arms of a molybdenum tungsten alloy capable of withstanding temperaw tures as high as $3000^{\circ} \mathrm{F}$ could be attached with knife edge clamps to either the shoulders or to the gage length section of the sample. These arms transmitted extension of the sample between the clamps to the extensometer measuring unit in a chamber below the furnace. The measuring unit was made up of an assembly of two levers and a pivot; which transmitted and magnified motion from anvils on the lower ends of the extension arms to a microformer pickup. Through $a$ combination of moving the pivot point on the levers and changing the magniflear tion range on the recorder, magnifications of from $25 \mathrm{X}$ to $1000 \mathrm{X}$ could be obtatned.

A slight modification of the lever and pivot assembly was made to eliminate binding of the levers in the pivot assembly. This also resulted in making the measuring unit completely separable from the arms so that after exhausting its measuring capacity, it did not have to be removed. The measuring capacity ranged from 0.04 inch at the highest magnification pivot position to 0.4 inch at the lowest magnification position.

The temperature detection system incorporated three Inconel-sheathed onesixteenth-inch diameter Chromel-Alumel thermocouples which passed into the furnace through three vacuum thermocouple lead-ins sealed with teflon inserts. The calibration of the thermocouple wire was $\pm 4^{\circ} \mathrm{F}$ from 0 to $530^{\circ} \mathrm{F}$ and $\pm 3 / 4 \%$ of the value above $530^{\circ} \mathrm{F}$. A thermocouple was embedded in both the upper and lower extensometer clamps and the third was attached to the middle of the gage length of the sample with a stalnless steel clamp. Temperature measurements were made with a Leeds and Northrup millivolt potentiometer.

The recording systems for load and elongation were combined in the Wiedemann MA1D recorder. The load was transmitted from the load indicator dial to the recorder by a rack and gear assembly. The signal from the extensometer microformer drove the motor of the chart drum for a record of extension. The signal from the extensometer also actuated a pointer in a Wiedemana MA-G19 Strain Pacer. Mounted coaxially with the pointer was a pacing disk connected to a variable gear train. In conjunction with the extensometer 
and recorder, the strain pacer assisted the operator of the testing machine in maintaining a constant rate of displacement between the extensometer knife edges. Rates ranging from 0.0025 inch per minute to 0.1 inch per minute could be selected.

\section{Experimental Procedure}

\section{Sample Preparation}

In developing the testing procedures, an evaluation was made of the elevated temperature mechanical properties in the alpha crystalline range of metal from a centrifugally cast hollow core. The chemical analysis of the additives in the uranium core was as follows:

$$
\begin{aligned}
& \mathrm{Fe}-174 \mathrm{ppm} \\
& \mathrm{Si}--320 \mathrm{ppm} \\
& \mathrm{C}--1200 \mathrm{ppm} \\
& \mathrm{H}_{2}=0.8 \mathrm{ppm} \text { (Before heat treatment) } \\
& \mathrm{H}_{2}--18 \mathrm{ppm} \text { (After heat treatment) }
\end{aligned}
$$

The heat treatment of the core consisted of a gamna phase soak in salt at $1475^{\circ} \mathrm{F}$ for 30 minutes and then cooling to room temperature under an argon atmosphere. This was followed by a beta soak in salt at $1350^{\circ} \mathrm{F}$, a ten second air delay, and a $130^{\circ} \mathrm{F}$ oil quench.

Fourteen one-quarter-inch diameter shouldered-end tensile specimens were machined from the core to the dimensions shown, in Figure 3 . The asmachined samples were mechanically polished to remove tool marks. The diameter of each sample was measured to the nearest thousandth of an inch and two diametrically opposed sets of gage marks $1.000 \pm 0.005$ inch apart were stamped on the reduced diameter section of the samples.

\section{Tensile Testing}

For an individual test, the sample train consisting of the sample, sample holders, pull rods and extensions, extensometer arms, and thermocouples was assembled. The extensometer knife edge clamps were attached to the sample gage length $1.000 \pm 0.001$ inch apart. The completed sample train was then lowered into the furnace. After the furnace was swung into testing position and suspended from its positioning pulley, the sample train and furnace were aligned. The extensometer measuring unit was positioned in its chamber and the vacuum system sealed and pumped down.

Once a vacuum of $10^{-4}$ torr was attained, the sample was heated to temperature in one hour. An additional hour at temperature was used to allow temperature equilibration of the sample to within $\pm 3^{\circ} \mathrm{F}$ of the aim point and to adjust the temperature profile along the gage length to.within $\pm 5^{\circ} \mathrm{F}$. The sample was then pulled at a strain rate of 0.02 inch per minute. A load-elongation record was made for each test. The extensometer magnification was $100 \mathrm{X}$ with a maximum measuring capacity of 0.4 inch. 
After fracture, the sample was allowed to furnace cool. On removal, the two pieces of the fractured sample were fitted back together and the reduced diameter \pm 0.001 inch and the elongated distance between the punched gage marks \pm 0.01 inch were measured.

3. Metallography

For metallography, the fracture surface and a longitudinal section of the sample at the fracture were mounted and ground through $600 \mathrm{grit}$ silicon carbide abrasive paper. This was followed by attack polishes with Linde $A$ and then Linde $B$ alumina suspended in dilute chromic acid. For bright and dark field metallography, the samples were electrolytically etched for ten seconds at 20 volts in a single orthophosphoric etchant consisting of five parts orthophosphoric acid, five parts ethylene gycol, and eight parts ethyl alcohol: An additional anodizing treatment of 4 to 5 seconds at 13 voits in $40 \%$ sodium citrate solution was given the samples for polarized light metallography. A sample of the metal in an unstrained condition was also examined. Photo-micrography was performed on a Bausch and Lomb metallograph equipped with a calcite prism for polarized light observation.

The macrograin structure of the metal stock from which the samples were machined was also examined. The macrograin structure was developed by etching for one minute in concentrated hydrochloric acid followed by five seconds in concentrated nitric acid. The macrostructure was photographed using a Bausch and Lomb Model L camera.

\section{Test Results}

\section{Mechanical Properties}

Two samples were tested at each temperature of $25^{\circ} \mathrm{C}, 100^{\circ} \mathrm{C}, 200^{\circ} \mathrm{C}, 300^{\circ} \mathrm{C}$, $400^{\circ} \mathrm{C}, 500^{\circ} \mathrm{C}$, and $600^{\circ} \mathrm{C}$. The ultimate tensile strength was calculated from the maximum load on the load-elongation curve and the original diameter of each sample. The effect of temperature on the ultimate tensile strength of the alloy is shown in Figure 4. Ultimate tensile strength decreased with temperature from a maximum at $25^{\circ} \mathrm{C}$. An inflection in the rate of decrease in strength with increase in temperature was evident at $200^{\circ} \mathrm{C}$ to $300^{\circ} \mathrm{C}$.

The percent reduction in area for the tests was calculated from the original and final diameter of the samples. In Figure 5 it is seen that from $25^{\circ} \mathrm{C}$ to $300^{\circ} \mathrm{C}$, percent reduction in area increased steadily with temperature. From $300^{\circ} \mathrm{C}$ to $400^{\circ} \mathrm{C}$, it increased at a greater rate and the increase became quite large above $400^{\circ} \mathrm{C}$.

The percent elongation in one inch was calculated from the averaged values of increase in length between the punched gage marks on each side of the sample. An increase in temperature increased the percent elongation as seen in Figure 6 . However, a plateau in the increasing percent elongation occurred at $300^{\circ} \mathrm{C}$. This phenomenon has been observed by other investigators.6,7 
In order to illustrate the stress-strain behavior of the sample better at different temperatures, the load-elongation curves were converted to true stress-strain curves. True stress is defined in terms of the instantaneous cross section of the sample rather than the original cross section. For true strain, the change in length due to an applied stress is referred to the instantaneous gage length rather than to the original gage length as is done for engineering strain. These two parameters may be calculated from the load-elongation curves by equations (1) and (2).

$$
\sigma_{T}=P / A_{O}(1+e)
$$

where

$$
\begin{aligned}
& \sigma_{\mathrm{T}}=\text { True stress in psi. } \\
& \mathrm{P}^{\mathrm{T}}=\text { Load in pounds. } \\
& A_{0}=\text { Original cross sectional area in square inches. } \\
& \mathrm{e}=\text { Engineering strain or the change in length } \\
& \text { divided by the original gage length. } \\
& \epsilon=\ln (1+e) \\
& \text { where } \epsilon=\text { True strain in inches per inch. } \\
& \text { e = Engineering strain. }
\end{aligned}
$$

Derivations of these two expressions may be found in the Appendix. Representative true stress-true strain curves for each test temperature are shown in the log-log plot of Figure 7 . The curves are incomplete for samples pulled at $500^{\circ} \mathrm{C}$ and $600^{\circ} \mathrm{C}$ because of slipping of the extensometer arms as locallzed deformation of the samples took place.

For many materials, a useful relationship to express the true stressstrain curve has been found to be the power function represented by Equation (3).8

$$
\boldsymbol{\sigma}_{T}=K \epsilon^{\mathfrak{n}}
$$

where

$$
\begin{aligned}
\sigma_{\mathrm{T}}= & \text { True stress in psi. } \\
\mathrm{K}= & \text { The strength coefficient in psi and it is the } \\
& \text { true stress at } \epsilon=1.0 . \\
\mathrm{n}= & \text { The strain hardening coefficient. It is the slope } \\
& \text { of a log-log plot of true stress-true strain and } \\
& \text { numerically equal to the strain at which localized } \\
& \text { deformation or "necking" takes place. }
\end{aligned}
$$

The power function in Equation (3) describing the true stress-strain curve is valid only from the beginning of plastic flow to the maximum load at which the onset of necking takes place. The localized deformation during necking voids the assumption of proportionality between change in cross sectlonal area and change in length used in deriving expressions for true stress and true strain (See the Appendix). Thus, the actual true stress and true strain become greater than the calculated true stress and true strain beyond the onset of necking. 
The values of the $K$ and $n$ parameters for the true stress-strain curves of each test along with the true strain at maximum load for comparison with $n$ are summarized in Table $I$. Also included in Table $I$ are the values of true fracture stress and true fracture strein. These two parameters are defined by Equations (4) and (5).

$$
\sigma_{f}=P_{f} / A_{f}
$$

where $\sigma_{f}=$ True fracture stress in psi.

$P_{f}=$ Load at fracture in pounds.

$A_{f}=$ Cross-sectional area of the sample at the point of fracture in square inches.

$$
\epsilon_{f}=\ln A_{o} / A_{f}
$$

where $\epsilon_{f}=$ True fracture strain.

$A_{0}=$ Original cross-sectional area of the sample in square inches.

$A_{f}=$ Cross-sectional area of the sample at the point of fracture in square inches.

At $500^{\circ} \mathrm{C}$ and $600^{\circ} \mathrm{C}$, the rate of decrease in ioad before fracture occurred was so rapid that the load at fracture could not be determined.

In Table $I$, it can be seen from the variation of $n$ with temperature that as temperature increased, the alloy strain-hardened less and thus became more plastic. At $25^{\circ} \mathrm{C}$ and $100^{\circ} \mathrm{C}$, the samples fractured before the onset of necking and, therefore, $n$ and true strain at maximum load were not equal. Instead, the true strain at maximurn load was equal to true fracture strain.

From $200^{\circ} \mathrm{C}$ to $400^{\circ} \mathrm{C}$, a comparison between $\mathrm{n}$ and the true strain at maximum load shows there is numerical equality between the two parameters. From Figure 7 at true strain values greater than the value of the strain hardening coefficient, the true stressostrain curves begin to fall below the lines described by the power function in Equation (3). However, the values of true fracture stress-strain fall on the lines extrapolated out beyond the onset of necking.

At $500^{\circ} \mathrm{C}$ and $600^{\circ} \mathrm{C}$, the strain hardening coefficient is 0 . This would seem to indicate that the samples tested at these temperatures did not work-harden and were in a fully plastic state. However, since $\mathrm{n}$ is a measure of the strain at which necking oceurs and the power function is invalid beyond this point, this conclusion is misleading.

As can be seen in Table I, although the values of true strain at maximum load for tests at $500^{\circ} \mathrm{C}$ and $600^{\circ} \mathrm{C}$ were not zero, they were quite small. Therefore, there is a small portion of the true stress-strain curve where strain hardening takes place between the start of plastic flow and the onset of necking. At these temperatures, the alloy was very sensitive to 


\section{TABLE I}

The True Stress-True Strain Properties of a Centrifugal Cast 174 ppm Fe; 320 ppm Si Dilute Uranium Alloys at Vartous Temperatures in the Alpha Crystalline Range

\begin{tabular}{|c|c|c|c|c|c|c|}
\hline $\begin{array}{c}\text { Temperature } \\
{ }^{\circ} \mathrm{C} \\
\end{array}$ & $\begin{array}{c}\text { Sample } \\
\text { Code } \\
\text { No. } \\
\end{array}$ & $\underline{10^{-3}}$ psi & $n$ & $\begin{array}{r}\epsilon \\
\text { at Max. Load } \\
\end{array}$ & $\times 10^{-\sigma_{f}}$ psi & $\epsilon$ \\
\hline \multirow[t]{2}{*}{25} & D1 & 191.05 & 0.205 & 0.049 & 101.82 & 0.048 \\
\hline & D3 & 192.57 & 0.208 & 0.046 & 99.92 & 0.044 \\
\hline \multirow[t]{2}{*}{100} & D2 & 164.98 & 0.168 & 0.122 & 105.65 & 0.133 \\
\hline & D10 & 165.28 & 0.169 & -- & 104.63 & 0.106 \\
\hline \multirow[t]{2}{*}{200} & D4 & 114.50 & 0.147 & 0.140 & 88.33 & 0.191 \\
\hline & $\mathrm{D} 11$ & 112.62 & 0.136 & 0.128 & 91.05 & 0.200 \\
\hline \multirow[t]{2}{*}{300} & D5 & 88.26 & 0.115 & 0.113 & 76.76 & 0.293 \\
\hline & D12 & 89.61 & 0.114 & 0.120 & 78.09 & 0.311 \\
\hline 400 & D6 & 63.85 & 0.078 & 0.079 & 58.68 & 0.434 \\
\hline$\because$ & D13 & 63.77 & 0.071 & 0.069 & $(65.12)$ & 0.451 \\
\hline \multirow[t]{2}{*}{500} & D7 & 24.61 & 0.000 & $(0.018)$ & -- & 1.271 \\
\hline & D14 & 23.17 & 0.000 & $(0.016)$ & -- & 1.365 \\
\hline \multirow[t]{2}{*}{600} & D8 & - & -- & -- & -- & 2.312 \\
\hline & D9 & 10.09 & 0.000 & $(0.01)$ & -- & 2.514 \\
\hline
\end{tabular}

Numbers in parentheses are uncertain values 
changes in strain rate, and it required approximately one minute of testing time to adjust the strain rate. The adjustments caused noticeable fluctuations in the load level and, therefore, the load-elongation curves in the region where the strain hardening coefficient should be measured were erratic. Assuming the relationship between the strain hardening coefficient and true strain at maximum load continues at these temperatures, a better measure of $n$ would be the approximate values of $\epsilon_{\mathrm{P}}$ Max

The effect of temperature on the flow stress of the alloy at different levels of strain and on the strength coefficient $\mathrm{K}$ is shown in Figure 8. The plot of the natural logarithm of true stress for various levels of strain versus the reciprocal of temperature in degrees Kelvin reveals two distinct regions of different flow stress behavior with a transition between the two at approximately $400^{\circ} \mathrm{C}$. This is similar to the change in the behavior of the hardness of uranium at about the same temperature. The transition in hardness has been attributed to some change in the mechanism of deformation. ${ }^{9}$ As the level of true strain was increased, it can be seen that the transition temperature decreased.

A useful expression for characterizing the effect of temperature on flow stress at constant strain and strain rate is presented in Equation (6). 10

$$
\sigma_{\mathrm{T}}=\left(\mathrm{c} \exp \frac{\mathrm{Q}}{\mathrm{RT}}\right) \text {. }
$$

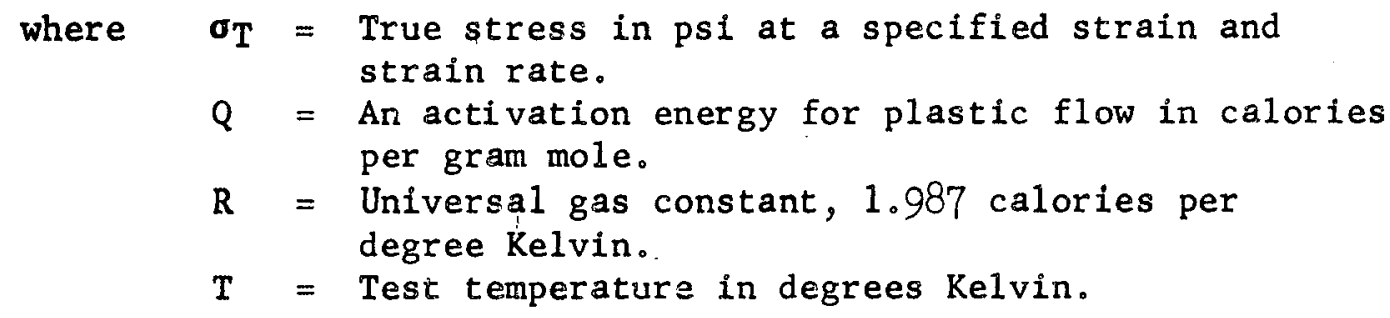

The values of $Q$ and $C$ at different strains for the two different mechanisms are summarized along with the transition temperature in Table II. Below the transition temperature, the activation energy for plastic flow is very small and increases with increasing strain. Above $i \dot{L}, Q$ is much larger and does not vary as much.

\section{Metallography}

The appearance of the samples after fracture is shown in Figure 9. Necking at the fracture point was not noticeable at test temperatures below $300^{\circ} \mathrm{C}$. The macrograin size of the core blank stock from which the samples were machined is shown for a longitudinal section and for transverse sections one-half inch apart along the length of the stock in Figure 10. The light area in the lower right hand corner of the longitudinal section is due to a large concentration of carbides in the pour tube end of the centrifugally-cast core. However, this concentration was contained in the shoulder of the test samples and did 


\section{TABLE II}

\section{Activation Energy for Plastic Flow vs. True Strain}

\begin{tabular}{|c|c|c|c|c|c|}
\hline \multirow[b]{2}{*}{$\epsilon$} & \multirow{2}{*}{$\begin{array}{c}\text { Transition } \\
\text { Temperature, }{ }^{\circ} \mathrm{C} \\
\end{array}$} & \multicolumn{2}{|c|}{ Below Transition Temp. } & \multicolumn{2}{|c|}{ Above Transition Temp. } \\
\hline & & $\mathrm{C} \times 10^{-3} \mathrm{psi}$ & Q, $\mathrm{kcal} / \mathrm{g}$ mole & $\mathrm{C} \times 10^{-3} \mathrm{psi}$ & Q, kcal/g mole \\
\hline 0.002 & 454 & 22.8 & 0.28 & 0.01 & 11.34 \\
\hline 0.010 & 396 & 36.5 & 0.39 & .07 & 8.71 \\
\hline 0.100 & 387 & 33.6 & 0.83 & .03 & 9.89 \\
\hline 1.0 & 383 & 28.3 & 1.31 & .02 & 10.55 \\
\hline
\end{tabular}


the slip plane. This hardening effect occurs over long distances and is relatively independent of temperature and strain rate. But strain hardenIng due to dislocation interactions occurs over distances less than five to ten interatomic distances. Thus, this effect can be overcome through thermal fluctuation, making it temperature and strain rate dependent.

As shown in Figure 8, two different regions of flow stress temperature dependence existed for the dilute uranium alloy tested. Below the transition temperature, the flow stress was comparatively unaffected by changes in temperature. However, there was a marked increase in the flow stress as the strain level was increased. Above the transition temperature, there was a large temperature dependence of flow stress which was independent of strain. These observations suggest that strain hardening in uranium below the transition temperature is primarily due to pile-ups of dislocation at barriers; above the transition it is mainly due to dislocation interaction.

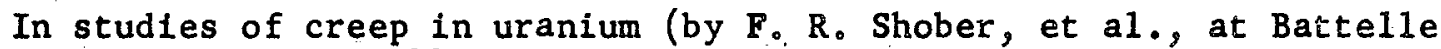
Memorial Institute) $)^{11}$ a simllar transition was found in the temperature dependence of the level of stress necessary to maintain a given creep rate. The transition temperature increased for increasing creep rates; e.g., $250^{\circ} \mathrm{C}$ for a creep rate of $1 \times 10^{-4}$ percent per hour and $370^{\circ} \mathrm{C}$ for a creep rate of 0.1 percent per hour. Below the transition, the stress necessary to maintain a given creep rate was comparatively unaffected by temperature. Above the transition, there was a marked increase in the effect of temperature on the stress. These observations are in agreement with the two proposed dislocation mechanisms controlling the strain hardening behavior of uranium.

At room temperature, the predominant mode of deformation in uranium has been identified by Cahn ${ }^{12}$ and Floyd and Chiswik ${ }^{13}$ to be (010)[100] slip with some (001)[100] cross-slip. A few other relatively unimportant slip systems were observed. Accompanying this slip was considerable twinning primarily on the [130] and [172] planes. Although the actual strain resulting from twinning has been found to be small compared with deformation by slip, twinning aids in rotating planes unfavorably oriented for slip into a more favorable position and relieves large stresses built up at grain boundaries. ${ }^{14}$ As with most metals that slip easily on only one plane, deformation of uranium at room temperature requires twinning to operate in order to retain coherence along grain and other twin boundaries. 15

Recent studies of deformation twinning have found that there is no critical resolved shear stress for twinning. Rather than being a competitive process. with slip, twinning and slip have been found to go hand in hand. Clear associations have been found between the twinning stress and dislocation pile-ups at barriers. ${ }^{16}$

In polycrystalline uranium, twins have been observed to form between grain boundaries or other twin boundaries. A proposed mechanism for this twin formation is as follows: At temperatures where twinning takes place, 
not affect testing results. The macrostructure corresponded to an FEDC grain size of $\mathrm{D} 6^{\mathrm{l}}$ and was constant along the length of the metal stock.

Figure 11 is a photomicrograph of the inclusion and precipitate distribution in an unstrained sample. The long dark thin inclusions are uranium hydrides formed during the gamma heat treatment in salt. The angular particles are uranium carbides and the large rounded particles are either uranium carbides or $\mathrm{U}\left(\mathrm{C}, \mathrm{O}_{2} \mathrm{~N}_{2}\right)$.

The behavior of these particles when the metal was deformed at various temperatures can be seen in Figure 12. Numerous voids associated with the particles were observed at temperatures from $25^{\circ} \mathrm{C}$ to $600^{\circ} \mathrm{C}$. At $500^{\circ} \mathrm{C}$ and $600^{\circ} \mathrm{C}$, the particles formed stringers parallel with the tensile axis when the metal deformed.

A more detailed examination of the particle behavior is shown in Figure 13. The carbides and hydrides were more friable than the surrounding matrix and fractured perpendicular to the tensile axis. At temperatures from $25^{\circ} \mathrm{C}$ to $400^{\circ} \mathrm{C}$, cracks formed in the matrix linking the fractured particles together. These cracks also ran perpendicular to the tensile axis. At $500^{\circ} \mathrm{C}$ and $600^{\circ} \mathrm{C}$, the fractured particles pulled apart leaving voids running parallel to the tensile axis.

The structure of the matrix of a longitudinal section of the sample adjoining the fracture as observed under polarized light is shown in Figure 14. Samples tested at temperatures from $25^{\circ} \mathrm{C}$ to $400^{\circ} \mathrm{C}$ evidence heavy twinning. Very little deformation of the grains can be seen. At $500^{\circ} \mathrm{C}$, the microstructure was partially recrystallized, and it was almost fully recrystallized at $600^{\circ} \mathrm{C}$. Aside from the recrystallization, some twinning was evident but the major results of deformation appeared to be very elongated grains with jagged grain boundaries. Cracks or voids were not observed associated with grain or twin boundaries, except when they were nucleated at fractured precipitates at the grain boundaries. Even when crack nucleation took place at particles at the boundaries, propagation of cracks took place through the matrix.

Discussion

1. Deformation Mechanisms

Strain hardening is the characteristic of a metal by which the shear stress required to produce slip continuously increases with increasing strain. From numerous studies of the stress-strain behavior of different metals, two different mechanisms of hardening due to dislocations have been observed. ${ }^{10}$ Strain hardening is caused by dislocations piling up at barriers which impede their motion or by interaction of dislocations with each other.

In polycrystalline material, slip is stopped at grain boundaries; dislocation pile-ups along the slip planes are formed at the boundaries. These pile-ups generate a back stress which opposes the applied stress on 
slip is stopped at the boundaries and dislocation pile-ups are formed at the boundaries along the slip planes; these pile-ups generate back stress which result in the nucleation of twins. Stresses necessary for twin nucleation in metals have been found to be greater than stresses necessary for propagation of twins; therefore, it would be difficult to observe twins growing from the boundaries.17

Ruedl and Amelinchx in an electron microscopic examination of uranium annealed at $500^{\circ} \mathrm{C}$ found hexagonal networks of disassociated nodes lying in the (001) plane, indicating a low stacking fault energy. 18 Croker has shown that these stacking faules are a result of the disassociation of perfect dislocattons with Bergers vectors of [100] and [110] into partials. 18

The process of cross-slip has been found to be more difficult in metals on planes with low stacking fault energies; $i_{\circ} e_{0}$, containing wide stacking faults. Also metals with low stacking fault energies twin more readily, strain harden more rapidly, and show a different temperature dependence of flow stress from metals, with higher stacking fault energies. 20

As has been noted, (001)[100] cross-slip has been observed in uranium associated with $(001)[100]$ slip. However, this cross slip occurred in the form of small jogs of short length in (010) slip bands. As temperature increased, the cross slip was observed more frequently and the (010) slip bands took on a wavy appearance. 12 This is consistent with the observation that stacking fault energies increase with increasing temperature thus decreasing the resistance to cross-silp. 21

The stacking fault energy of a metal is a function of the atomic binding in the lattice. ${ }^{22}$ Because of the peculiar binding arrangements between atoms in the orthorhombic crystal structure of alpha uranium, comparisons between it and metal with more orthodox binding arrangements may be invalid. However, assuming that stacking faults do influence the crossslip behavior of uranium as it does in other metals, the change in binding from convalent to ionic proposed by Friedel with increased temperature ${ }^{23}$ could significantly affect the cross-slip behavior.

At $600^{\circ} \mathrm{C}$, Chiswik, et al., found (001)[100] slip to be the predominant mode of deformation as compared with its occurrence only as cross-slip at room temperature. ${ }^{24}$ The critical resolved shear stress for this slip was estimated to be less than one-tenth of that for $(010)[100]$ s1ip. He also found that the critical resolved shear stress for (010)[100] slip was reduced only $15 \%$ from its value at room temperature.

Both Cahn $^{12}$ and Butcher ${ }^{25}$ in elevated temperature studies of deformation of uranium found that twinning as an important mode of deformation disappeared at temperatures above $450^{\circ} \mathrm{C}$ and $500^{\circ} \mathrm{C}$. This is similar to the change in deformed microstructure between $400^{\circ} \mathrm{C}$ and $500^{\circ} \mathrm{C}$ in Figure 14. 
Butcher postulated three possible reasons for this occurrence:

1. An increase in the number of slip modes;

2. A relative decrease in the critical resolved shear stress for slip compared with that for twinning;

3. An increase in grain- and polygon-boundary slip with a decreased need for twinning.

As Butcher pointed out, all the slip systems seen at elevated temperatures had also been observed at room temperature, although much less frequently.

The second possibility is most probable in that the critical resolved shear stress for slip decreases with increase in temperature. A relative. increase in the importance of slip systems at elevated temperature would thus reduce the need for twinning. At recovery temperatures where thermal fluctuations can assist in unlocking dislocations, the critical resolved shear stress is lowered considerably and thus slip assumes a much greater role in deformation processes. ${ }^{24}$

As for grain boundary sliding being important for a decrease in twinning, this is another way of saying that increased slip causes the disappearance of twins. It has been found that grain boundary sliding can only take place at recovery temperatures and when slip is occurring throughout the interior of the grain. In Figure 14 for $500^{\circ} \mathrm{C}$ microstructures, it can be seen that the grain boundarles of the elongated grains have been serrated. It has been proposed by researchers at the University of Florida that this serration is due to "packetized" slip or slip crossing the grain boundaries producing jogs in the boundaries. ${ }^{28}$ Another explanation could be that the boundaries slip in steps just as slip within the grains takes place.27

\section{Fracture}

From Figures 5 and 6 , it can be seen that the ductility of uranium increases only quite slowly in the range of $25^{\circ} \mathrm{C}$ to $300^{\circ} \mathrm{C}$. This phenomenon is due to the brittle to ductile fracture transition as has been well established by many observers. Taplin and Martin ${ }^{28}$ found that for fairly pure uranium, the transition began at $-190^{\circ} \mathrm{C}$ and finished at about $50^{\circ} \mathrm{C}$. Small additions of iron and aluminum as well as increased irregularity of the grain boundaries slowed down the rate of increase in ductility with temperature thereby shifting the end of transition to temperatures as high as $300^{\circ} \mathrm{C}$.

Studies of the effect of heat treatment of uranium samples in different media showed that salt treatments reduced their ductility. ${ }^{20}$. This effect was ascribed to pickup of hydrogen during the salt soak as took place in the heat treatment of the metal for these tests. An investigation of the effect of hydrogen by Marsh, et al., ${ }^{30}$ on the fracture transition in 
uranium found that increased levels of hydrogen significantly increased the transition temperature range.

As was illustrated in Figures 12 and 13 , cracks were formed in the matrix of the metal originating from ruptured carbides. Thus, the high carbon level provided many carbides as sites for the initiation of fracture. From $25^{\circ} \mathrm{C}$ up to $300^{\circ} \mathrm{C}$, plastic deformation was too small to relieve the stress concentrations at the particles in the matrix and thus cracks propagated thru the cross section of the sample.

This can best be seen for samples pulled at $25^{\circ} \mathrm{C}$ and $100^{\circ} \mathrm{C}$ where fracture took place before the onset of necking. At $200^{\circ} \mathrm{C}$ and $300^{\circ} \mathrm{C}$, some necking took place and the cracks in the matrix spread apart somewhat. However, in the region where necking takes place in a tensile sample, a triaxial state of stress is ultimately built up. This final condition raises the level of flow stress necessary to produce plastic deformation thus favoring propagation of cracks in a brittle manner. 31

In Figure 6, a plateau in the increase in percent elongation with temperature is evident at $300^{\circ} \mathrm{C}$. A possible explanation of this effect is that the method of measuring percent elongation along the gage length does not take into account the increase in length along the radius of curvature of the neck. As a result, the percent elongation may under state the actual ductility, whereas the percent reduction in area would be a better measure of ductility. As can be seen in Figure 5, there is not a plateau in the temperature dependence percent reduction in area at $300^{\circ} \mathrm{C}$. However, other researchers have noted not just a plateau but a minimum in both the percent reduction in area and the percent elongation at about this temperature. ${ }^{32}$ Some observers have attributed this behavior to. the formation of microcracks at the uranium grain boundaries; however, these cracks have not been identified. ${ }^{26}$

At $400^{\circ} \mathrm{C}$, fracture was most probably a mixture of brittle and ductile behavior. At $500^{\circ} \mathrm{C}$ and $600^{\circ} \mathrm{C}$, the carbide particles again played a role in fracture but in this case the ruptured carbide pulled apart forming voids between them. As the samples necked down, these voids coalesced in the neck, thus instituting ductile fracture.

\section{PROLONGED HOT HARDNESS TEST ING}

\section{Introduction}

Hot hardness testing presents a simple and inexpensive means of exploring the resistance to flow of uranium at elevated temperatures. Whereas hardness as a property is defined as the resistance of a metal to indentation, results may be influenced by the amount of time under load due to change in resistance with time. Investigators have found that if the indentation time is prolonged, the plastic deformation resulting from an indentor sinking into the material may be considered a form of compressive creep. $33_{3}, 34$ 
With this in mind, a prolonged hot hardness test was designed with the stipulation that the test temperature, load, time, and indentor size and shape be held constant. It was hoped that the indentation diameter resulting from the test could be used as a qualitative measure to rank alloys of differing composition and thermal and fabrication histories as to their creep resistance.

Experimenta1 Work

1. Test Conditions

The temperature selected for the test was $400^{\circ} \mathrm{C}$ since this temperature was within the thermal range at which cavitational swelling in uranium had been observed. A test load of 600 pounds and a $10 \mathrm{~mm}$. spherical indentor were chosen to give large, easily measured indentations. In order that tests might be run on a twenty-four-hour cycle basis yet allow enough time for significant creep to take place, a twenty-two-hour indentation time was adopted.

2. Hot Hardness Tester Design

Two different testers were used in this work. Most of the work was done using a spring-loaded tester. However, the loading characteristics of this tester proved to be of 1 imited usefulness. The load had to be applied before heating to test temperature and load applications of very short duration could not be made. Since it was desired to perform some scoping tests as to the effect of different loads and different times under load, a lever-loaded tester was also developed.

The design of the spring-loaded tester is shown in Figure 15. It consisted of a well in which the sample could be sealed under an inert atmosphere as a compressive load was applied and maintained by a spring. By varying the deflection of the spring, different loads could be applied.

The sample holder was attached to the lower end of the loading rod. It held two samples with a hardened steel ball between them. Small springs on the sample holder kept this configuration in place. The loading rod passed through a sliding " 0 " ring seal in the top of the well. On its upper end was a flange against which the compression spring acted. The load actuator above the spring was driven down against it with a loading handle screwed through the upper cross bar. The two outside rods acted as guide rods for the loading actuator and as loading columns between the cross bar and the top of the well.

When assembled, the well and well top were bolted together with an " 0 " ring seal between them. An argon inlet and thermocouple tube passed through the well cover. A 1/16-inch-diameter inconel sheathed, CromelAlumel thermocouple was located in the thermocouple tube with its end positioned near the center of the sample configuration. The calibration of the thermocouple wire was $\pm 4^{\circ} \mathrm{F}$ up to $530^{\circ} \mathrm{F}$ and $\pm 3 / 4 \%$ of the value above $530^{\circ} \mathrm{F}$. The thermocouple tube also acted as the argon outlet. 
The lever-loaded tester is shown in Figure 16. The lower portion of the tester was the same as in Figure 15, except for the use of a tungsten carbide ball as the indentor. The loading column system was eliminated and two knife edge " $V$ " grooves mounted in a rotating cross bar were added to the top of the loading rod. Loading was accomplished by placing. the well and loading rod assembly into a framework to which was attached a long lever arm. The lever arm had knife edges projecting from each side a short distance away from its fulcrum attachment on the framework. When lowered onto the tester, the knife edges fitted in the " $V$ " grooves on the top of the loading rod. The weight of the lever itself applied a load of 100 pounds to the tester.

For greater loads, weights were hung on the end of the lever. By varying the distance from the fulcrum at which a particular weight might be placed, any specific load could be applied. A steel meter rule was bolted to the lever to insure accurate positioning of the weight holder.

The lever system was calibrated at 400,600, and 800 pound loads to within \pm 1 pound. The general reproducibility of applied load was \pm 2 pounds. Calibration was made with a Toledo 1200-pound scale positioned on the lower cross bars of the loading framework. The top of the well was raised off the framework and the bottom rested on the scale. Thus, the load was transmitted from the lever through the tester to the scale. The amount of friction due to the sliding " 0 " ring seal where the loading rod passed through the well top is not known.

Heating was accomplished in a 5-inch-diameter, 12-inch-deep resistance heated, stirred, liquid solder bath. The solder bath provided fast heating rates and stirring eliminated thermal gradients within the bath. Temperature control was provided by a Honeywell Electronik 18 Recorder and Electr-0-Pulse 18 Controller. The control thermocouple was located in a well on the side of the pot between the pot and resistance heating elements. Temperature measurements were made with a Leeds and Northrup millivolt potentiometer and a continuous record of temperature was provided by Leeds and Northrup Speedomax $\mathrm{H}$ Recorder.

An inert atmosphere of argon was passed through a drying agent before introduction into the tester. A calibrated rotameter flow meter was used to control gas flow.

\section{Sample Preparation}

The chemistry, fabrication, and thermal history of the dilute uranium alloys tested are summarized in Table III. Samples for the test were 3/8-inch thick, 1/2-inch wide; and 1-inch long. The opposing faces of each of the samples were machined on a lathe to insure uniformity in thickness. The test surface of the sample was ground on 180 through 600 grit silicon carbide abrasive paper to remove machining marks and deformed material resulting from machining. 


\section{TABLE III}

The Chemistry, Fabrication, and Thermal History of the Dilute Uranium Alloys for Prolonged Hot Hardness Testing

\begin{tabular}{|c|c|c|c|c|c|c|c|c|c|}
\hline \multirow{2}{*}{$\begin{array}{c}\text { Alloy } \\
\text { Designation } \\
\end{array}$} & \multicolumn{5}{|c|}{$\begin{array}{l}\text { Additive } \\
\text { Chemistry in } \mathrm{ppm}^{\mathrm{b}} \\
\end{array}$} & \multicolumn{2}{|c|}{$\begin{array}{l}\text { Total Additivec } \\
\text { Concentration in ppm }\end{array}$} & \multirow{2}{*}{$\begin{array}{c}\text { Type } \\
\text { Extrusion } \\
\end{array}$} & \multirow{2}{*}{$\begin{array}{l}\text { Heat } \\
\text { Treatment } \\
\text { Treat }\end{array}$} \\
\hline & $\mathrm{Fe}$ & $\underline{s i}$ & Al & Cr & Mo & Actual & Adjusted & & \\
\hline$D-1$ & 150 & 110 & -- & -- & -- & 260 & 260 & Alpha & S-O \\
\hline$I-2$ & 150 & 110 & -- & -- & -- & 260 & 260 & Gamma & $S-0$ \\
\hline$D-3$ & 170 & 123 & -- & -- & -- & $293^{\circ}$ & 293 & Alpha & S-O \\
\hline D-4 & 172 & 128 & -- & -- & -- & 300 & 300 & Gamma & $s-0$ \\
\hline$D-5$ & 150 & 100 & 140 & -- & -- & 390 & 390 & Alpha & S-0 \\
\hline$D-6$ & (64) & 370 & -- & 240 & -- & 674 & 674 & Alpha & $s-0$ \\
\hline I-7 & (90) & 350 & -- & 260 & -- & 700 & 700 & Alpha & $\begin{array}{l}S-S \\
S-0 \\
S-S \\
S-W\end{array}$ \\
\hline & & & & & & & $\cdots$ & & S-A \\
\hline D-8 & (64) & 890 & -- & -- & -- & 954 & 954 & Alpha & s-o \\
\hline D-9 & (67) & 360 & 1000 & $\therefore$ & -- & 1427 & 760 & Alpha & $s-0$ \\
\hline D-10 & 220 & 370 & 870 & -- & -- & 1460 & 902 & Gamma & S-S \\
\hline D-11 & 250 & 270 & 300 & 240 & -- & 1060 & 1060 & Alpha & s-o \\
\hline$I-12$ & 250 & 260 & 180 & 280 & -- & 970 & 970 & Alpha & $\begin{array}{l}S-S \\
S-0\end{array}$ \\
\hline & & & & & & & & & S-S \\
\hline & & & & & & & & & S-W \\
\hline & & & & & & & & & S-A \\
\hline D-13 & 220 & 240 & 910 & 200 & -- & 1670 & 1066 & Alpha & S-0 \\
\hline I-14 & 230 & 320 & 680 & 220 & -- & 1450 & 1120 & Alpha & $s-0$ \\
\hline & & & & & & & & & $\begin{array}{l}S-S \\
S-W\end{array}$ \\
\hline & & & & & & & & & S-A \\
\hline D-15 & 230 & 410 & 890 & 220 & -- & 1750 & 1170 & Gamma & S-S \\
\hline
\end{tabular}


4. Experimental Procedure

Initial loading of the spring tester was done on a Baldwin Tate Emery Universal testing machine. After insertion of the samples and ball in the sample holder and assembly of the tester, a yoke was fitted over the upper loading framework to wing extensions on the load actuator. The unit was then placed between the lower cross head and table of the testing machine and a 600-pound compressive load applied. Next, the loading handle was screwed down flush with the top of the load actuator and tightened one-eighth of a turn to transfer the load from the machine to the tester.

After the tester had been purged with argon, the tester well was immersed three quarters of its length in the liquid solder bath. Approximately one-half hour was required for the samples to reach temperature. A three cubic foot/hour flow of argon was maintained throughout the test. Twenty-two hours from the time of insertion in the bath the tester was removed and quenched into water.

For the lever tester, the assembly was purged with argon and set in the loading framework immersing it in the solder bath under the framework. The load was not applied for one hour after immersion to allow temperature equilibration of the samples.

The loading procedure consisted of first positioning the lever on top of the loading rod and then applying the major load by slowly lowering the weight assembly. with a jack until it was hanging from the lever arm. The test duration was timed from the application of the major load. After twenty-two hours, the major load was removed by jacking up the weight hanger and removing the lever. The tester was then quenched into water.

\section{Scoping Tests}

A few tests were performed to determine the effect of varying load, time, temperature, and indentor size. Two alloys were selected that had been beta treated in molten salt and oil quenched, representing the lowest (D1) and the highest (I-18) alloy contents, respectively, of the total array tested. The effects of different loads and indentation diameters were studied at room temperature. Several different types of conventional hardness testers and three ball diameters were used. The hardness testers, loads, and ball diameters are listed in Table IV.

In these tests, the load was applied for one minute. In the case where a minor load was applied as with the lever and Rockwell testers, the sequence of loading was minor load for 20 seconds, total load for one minute, and minor load for another 20 seconds. Two indentations were made on the samples for each set of conditions and their results averaged.

A few tests were also run at $400^{\circ} \mathrm{C}$ to determine the effect of varying load. Only the lever tester with a $10 \mathrm{~mm}$. tungsten carbide ball was 
TABLE III (Cont.)

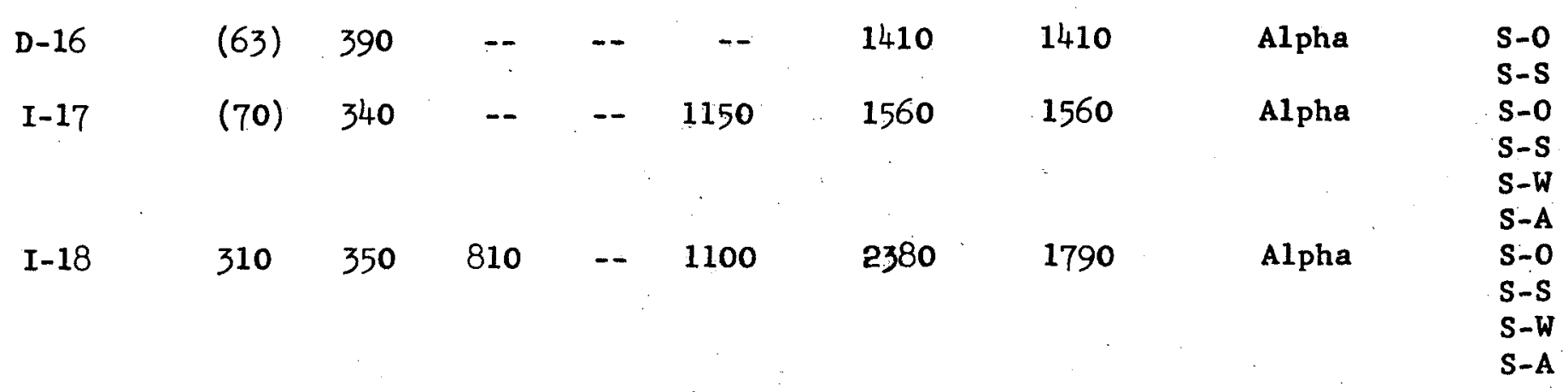

a D - Dingot Metal, Carbon Level $\approx 40 \mathrm{ppm}$.

I - Ingot Metal, Carbon Level $\approx 600 \mathrm{ppm}$.

b Figures in parentheses are normal impurity levels.

c Adjusted totals excluded $\mathrm{A} 1>400 \mathrm{ppm}$ and $\mathrm{Fe}$ in the ratio of $3 \mathrm{ppm} \mathrm{Fe}$ to $16 \mathrm{ppm}$ Al for Al content $>400 \mathrm{ppm}$.

d All heat treatments began with a 10 -minute beta soak at $732^{\circ} \mathrm{C}$ followed by various quenches:

(S-0) - 10-second air delay, quench in $55^{\circ} \mathrm{C}$ oil.

(S-S) - 10-second air delay, quench into $500^{\circ} \mathrm{C}$ salt and hold for 2 minutes, 10-second air delay, quench into water.

$(S-W)$ - 10-second air delay, quench in water.

(S-A) - air cool. 
Hardness Testers, Indenter S1zes, and Loads Used to Determine the Effect of Various Loads and Indenters on the Indentation Behavior of Alloys D-1 and D-18

\begin{tabular}{|c|c|c|c|c|}
\hline Hardness Tester & $\begin{array}{l}\text { Tungsten Carbide } \\
\text { Ball Diameter, mm. }\end{array}$ & $\begin{array}{l}\text { Load In } \\
\text { Pounds } \\
\end{array}$ & $\begin{array}{l}\text { Load in } \\
\mathrm{Kg} \\
\end{array}$ & $\begin{array}{l}\text { Alloy } \\
\text { Tested }\end{array}$ \\
\hline \multirow[t]{3}{*}{ Lever Tester } & 10 & 400 & 182 & $D-1 \& I=18$ \\
\hline & & 600 & 272 & $D-1 \& I-18$ \\
\hline & & 800 & 363 & $D-1 \& I-18$ \\
\hline \multirow[t]{5}{*}{ King Portable Brinell } & 10 & -- & 500 & $\mathrm{I}-18$ \\
\hline & & & 750 & $I-18$ \\
\hline & & & 1000 & $I-18$ \\
\hline & & & 1500 & $\mathrm{I}-18$ \\
\hline & & & 3000 & $\mathrm{I}-18$ \\
\hline \multirow[t]{6}{*}{ Rockwell } & 3.175 & -- & 60 & $D-1 \& I-18$ \\
\hline & & $-\infty$ & 100 & $D-1 \& I-18$ \\
\hline & & -- & 150 & $D-1 \& I-18$ \\
\hline & 1.588 & - & 60 & $I-18$ \\
\hline & & - & 100 & $I-18$ \\
\hline & & -- & 150 & $I-18$ \\
\hline
\end{tabular}


used. The loads used were the same as in Table III for the lever tester and the loading procedure identical with that outlined above.

Scoping tests were also made to determine the effect of time under a 600 -pound load at $400^{\circ} \mathrm{C}$ using the lever tester. . The procedure of testing was the same as for the $400^{\circ} \mathrm{C}$, one-minute tests; the duration being measured from the time of application of the load. Two tests with samples of both of the alloys included in each test, were run for each of a sequence of indentation times, these were: one minute, four hours, sixteen hours, and twenty-eight hours, respectively.:-

No tests were made to determine the effect of different temperatures on indentation diameter. However, samples from rejected tests that exceeded $405^{\circ} \mathrm{C}$ for short periods of time showed much larger indentations indicating a marked temperature dependence.

\section{Indentation Measurement}

The indentations resulting from tests. with the spring tester were photographed at a magnification of $24.0 \mathrm{X}$ using a Bausch and Lomb Model $\mathrm{L}$ camera. A slight polish was given the samples before photographing them using Linde $B$ alumina suspended in distilled water to remove oxidation on the surface of the sample and to delineate the edge of the indentations. A photograph of a representative specimen is shown in Figure 17 . The white rim around the edge of the indentation is a ridge of metal extruded from beneath the indentor ball during testing. Eight measurements of the diameter between the inside edge of the rim were made from the photograph at increments of 45 degrees around the circumference of the sample and the results averaged as the diameter of indentation \pm 0.001 inch.

In the process of examining the indentations in this manner, some very irregular indentations were observed. These irregularities were due to deformation spots on the hardened steel balls formed during previous tests. The tests in which this irregularity was observed were not included in the results. In the later tests using the lever tester, tungsten carbide balls were used which avoided this problem.

An analysis of several photographs caken of the same indentation revealed a slight but statistically real difference in measurements made on different photographs due to stretching of the paper. For this reason, indentations resulting from tests with the lever tester and from the scoping tests were measured using a filar eyeplece in conjunction with the optics and microstage of a Tukon hardness tester. The measuring setup was calibrated to within \pm 0.0001 inch. 


\section{TEST RESULTS}

1. Prolonged Hot Hardness Test

The indentations for the dilute uranium alloys investigated by the prolonged hot hardness test using the spring tester have been displayed in graphical form, with the data derived from water-quenched and oilquenched core blanks presented in Figure 18 and the results for aircooled and salt-quenched cores plotted in Figure 19. In determining the effect of additives on the results of the test, it was assumed that the hardening effect of an additive was limited to its solubility in beta uranium at $732^{\circ} \mathrm{C}$. (the control point for beta heat treatment). Larger concentrations would result in some of the additive remaining as precipitate during beta treatment and thus be unavallable for solution hardening on quenching. Since diffusion is rapid in the beta range, agglomeration of precipitates not taken into solution would prevent significant precipitate hardening. At the test temperature of $400^{\circ} \mathrm{C}$, diffusion is slow: therefore precipitation of the additives quenched from a solution temperature should not take place to harden the material.

For the alloys tested, except for the aluminum alloys containing more than $400 \mathrm{ppm}$, the high silicon alloy, and the high molybdenum alloys, the additive levels were within their solubility limits in beta uranium at $732^{\circ} \mathrm{C}$.

The solubility of aluminum in beta uranium at $750^{\circ} \mathrm{C}$ has been found to be about $400 \mathrm{ppm}^{35}$ The $890 \mathrm{ppm}$ silicon alloy is quite close to its solubility limit. Although the solubility of molybdenum is not known, an examination of the microstructure as shown in Figure 20 of salt-oil heat-treated Alloy $D-16$, revealed fine precipitates in the matrix indicating that some of the molybdenum was not solubilized during the beta heat treatment. The quantity of precipitate was small, however, and it was assumed that almost all of the molybdenum was in solution.

An additional effect decreasing the amount of an additive available for solution hardening takes place in the high aluminum alloys containing iron. Investigations of the uranium-iron-aluminum ternary system at MCW revealed a marked solubility of iron in $\mathrm{UAl}_{2}{ }^{35}$ At $750^{\circ} \mathrm{C}$, the solubility of iron in $\mathrm{UAl}_{2}$ was found to be approximately in the ratio of 2 mols of Fe for every 28 mols of Al concained in UAla.

With the preceding discussion in mind, an "adjusted total alloy content" available for solution hardening was calculated for the different alloys using the following criteria:

1. For $\mathrm{Si}, \mathrm{Cr}$, and Mo, include actual additive levels.

2. For high Al alloys, exclude A1 greater than $400 \mathrm{ppm}$ from the total. 
3. For high Al alloys containing $\mathrm{Fe}$, exclude $\mathrm{Fe}$ in the ratio of $3 \mathrm{ppm} \mathrm{Fe}$ for every $16 \mathrm{ppm} \mathrm{Al}$ above an Al level of $400 \mathrm{ppm}$.

The "adjusted total alloy content" is included in Table III and is plotted on the log ordinate of the graphs of adjusted total alloy content versus indentation diameter in Figures 18 and 19. From Figure 18, it can be seen that the prolonged hot hardness indentation diameter for severely quenched material decreased as the $10 \mathrm{~g}$ of the "adjusted total alloy content" increased. In Figure 19, there is quite a bit of scatter, but the general trend is the same. Comparing the two figures, it can be seen that the more severe quenches, in general, resulted in smaller indentations. This is conceivable due to increased hardness of the uranium from plastic deformation of the grains during the severest quenches. There is no discernible difference between alpha and gamma extruded alloys or between the low carbon dingot alloys and the high carbon ingot alloys.

\section{Scoping Tests}

The results of the room temperature hardness tests with different hardness testers, loads, and indentors are summarized in Figure 21. The indentation diameters and loads for tests using indentors smaller than $10 \mathrm{~mm}$. were converted to values that would have yielded equal hardness if a $10 \mathrm{~mm}$. diameter ball had been used. The conversion was based on the physical principle of geometrically similar indentations and on the empirically derived hardness relationship known as Meyer's Law. ${ }^{36}$

The physical relationship of geometrically similar indentations states that hardness tests using spherical indentors of different diameters (D) will yield the same hardness value when the indentation diameters (d) bear a common relationship to the respective indentor diameters. When this occurs, conditions exist as in Equation 7 .

$$
\frac{d_{1}}{D_{1}}=\frac{d_{2}}{D_{2}}
$$

Meyer's Law predicted in 1908 that if different loads were used to force an indentor into a material, a relationship would exist between the load and indentation diameter as expressed in Equation 8.

$$
\mathbf{W}=\mathbf{K d}^{\mathrm{n}}
$$

where $\mathrm{W}=$ Load in $\mathrm{Kg}$

$\mathrm{d}=$ Diameter of indentation in $\mathrm{mm}$.

$K=A$ constant of the material and is the load value at $\mathrm{d}=1$.

$\mathrm{n}=$ Constant of the material (actually by definition $n$ is the slope of a log-log plot of load versus indentation diameter).

Meyer's Law also stated that if balls of different diameters $D_{1}$ and $D_{2}$ were used, the index $n$ was almost independent of the ball diameter and only the value of $\mathrm{K}$ varied so that a relationship existed as in Equation 9. 


$$
A=K_{1} D_{1}^{n-2}=K_{2} D_{2}^{n-2}
$$

where $\quad A=$ A constant

From Equations 8 and 9, we may write an expression relating load, ball diameter, and indentation diameter for a particular material.

$$
\frac{W}{D^{2}}=A \quad\left(\frac{d}{D}\right)^{n}
$$

From the principle of geometrically similar indentations as stated in Equation 7 , it can be seen that to have equal hardness using balls of two diameters, the ratio of load to ball diameter squared must be constant or

$$
\frac{W_{1}}{D_{1}^{2}}=\frac{W_{2}}{D_{2}^{2}}=C
$$

Using Meyer's analysis, the values of $K$ and $n$ were determined for tests performed with tungsten carbide balls of less than $10 \mathrm{~mm}$. diameter. These values were used to compute the constant $A$ and in turn evaluate the diameters of indentation that would have been geometrically similar if a 10-mm. ball had been used. Likewise, the load that would have been necessary to produce a geometrically similar indentation was calculated using Equation 11.

As can be seen in Figure 21, the corrected values of load and indentation agree well with values obtained with a 1.0-mmodiameter indentor. The Meyer's index $\mathrm{n}$ and the parameter $\mathrm{K}$ for the two alloys were as follows: for $\mathrm{D}-1, \mathrm{n}=2.48$ and $\mathrm{K}=99.8 \mathrm{~kg} \circ$; for $I-18, \mathrm{n}=2.31$ and $\mathrm{K}=145 \mathrm{~kg}$. Comparing the values of $\mathrm{n}$ for the two alloys, the increase in diameter of indentation with increasing load is greater for alloy D-1. Thus at higher levels of load, the difference between the indentation diameters produced by a particular load decreases for the two alloys rested.

Indentation diameters determined at $400^{\circ} \mathrm{C}$ under different loads for one minute are also included in Figure 21. The rests were made only in the lever tester with a 10-mm.-diameter tungsten carbide ball so there are too few results to perform an accurate Meyer's analysis.

The effect of time under 600 -pound load at $400^{\circ} \mathrm{C}$ using $10-m m$. tungsten carbide ball as the indentor is shown in Figure 22 . The points represent the average of two tests for each loading time.

The diameter of indentation increases at a faster rate with loading time for Alloy $D-1$ than for I-18. A rapid increase is evident above times greater than four hours for both the alloys. The reason for this behavior is unknown. 


\section{Discussion}

The prolonged hot hardness test as performed on several dilute uranium alloys appears to be directly related to solid solution hardening by the additives. It is not evident that the test is a measurement of creep resistance.

The hazards of using a singled valued result for ranking many different alloys with different histories may be glimpsed in the scoping tests performed on Alloys $D-1$ and I-18. The two alloys show different responses to load and time under load. It is concelvable that the ranking of two alloys as to their resistance to indentation could be reversed by changing the condition of the test.

The temperature chosen for the test is within the range for cavitational swelling; however, in order to describe fully the behavior of different alloys, tests should be made over a range of temperatures.

Lastly, as to the hoped-for use as a method of predicting reactor performance, the behavior of alloys during the prolonged hot hardness test did not correspond to that observed in reactor fuel. As has been noted, the resistance to indentation can be directly related only to those additive levels that can solution-harden the uranium. McDonne11 and Angerman in their report ${ }^{37}$ on the effect of additives on the cavitational swelling threshold of uranium observed that under irradiation additives that had previously existed as precipitates were taken into solution. Thus, alloys whose additives could be quenched into solution performed no better than high-level-saturated dilute uranium alloys, indicating that reactor performance is closely related to total soluble alloy content. 


\section{REFERENCES}

1. Angerman, C. L., and Caskey, G. R., Jr., "Swelling of Uranium by Mechanical Cavitation," Journal of Nuclear Materials 13, No,. 2 (1964), p. 182-196.

2. Chiswik, H. H., "The Plastic Deformation of Uranium on Thermal Cycling," Trans. ASM 49 (1957), p. 622-54.

3. McDonne11, W. R., "Development of Swelling-Resistant Uranium Alloys," Nucleonics (October, 1965), p. 72.

4. Underwood, E. E., "Creep Properties from Short Time Tests," Materials and Methods (April, 1957), p. 127-9.

5. Larson, F. R., and Miller, J., "A Time-Temperature Relationship for Rupture and Creep Stress," Trans. ASM 74 (1953), p. 765.

6. Lanlesse, J., "Mechanical Properties of Low' Concentration Uranium Alloy," Mem. Sc1. Rev. Met. 61 (November, 1964), p. 761-7.

7. Lemogne, André, et al., "The Plastic Behavior of Polycrystalline Uranium Between $\overline{20^{\circ}}$ and $-196^{\circ} \mathrm{C}$," Academie Des Sclences, Paris Comptes rendus 257 (September, 1963), p.'2032- $\overline{35 .}$

8. Dieter, G. E., Jr., Mechanical Metallurgy, McGraw-Hili Book Company, New York (1961), p. 56 .

9. Chub, W., "A Method of Measuring the Contribution of Crystal Structure to the Hardness of Metals," U.S.A.B.C. Report BMI-X-112, Battelle Memorial' Institute (1953).

10. Dieter, G. E., Jr., Mechanical Metallurgy, P. 111-7 and 120-1.

11. Schober, F. R., et al, Battelle Memorial Institute in Holden, $A$, N., Physical Metallurgy of Uranlum, Addison-Wesley Publishing Company, Reading, Massachusetts (1958), p.. 74 .

12. Cahn, R. W., "Plastic Deformation of Uhanium," U.K.A.E.A. Report A.E.R.E.-M/R-740, Atomic Energy. Research Establishment, Harwell (2951).

13. Lloyd, L. T., and Chiswik, H. H., "Deformation Hechanisms of Alpha Uranium Single Crystals," Trans. Am. Inst. Mining Met. Engrs. 203 (1955), p. 1206.

14. Reed-Hi11, R. E., "Role of" Deformation Twinning in the Plastic Deformation of a Polycrystalline Anisotropic Metal," Reed-Hi11, R. E., et al., Editors, Deformation Twinning, Cordbn and Breach Science

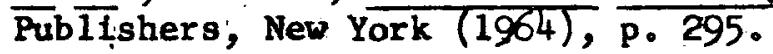


15. McLean, D., Mechanical Properties of Metals, John Wiley and Sons, Inc., New York (1962), P. 128.

16. Cahn, R. W., "Survey of Recent-Progress in the Fleld of Deformation Twinning," Reed-Hi11, R. E., et al., Editors, Deformation Twinning, P. $1-17$.

17. Cahn, R, w., Deformation Twinning, p. 1-17.

18. Rued1, E., and Amelinckx, "Electron Microscoplc Observation of Dislocation Networks and Radiation Damage in Alpha Uranium," J: of Nuclear Materials 2, No. 1 (1963), p. 116-119.

19. Croker, A. G., "Stacking Faults in Alpha Uranium," J. of Nuclear Materials 15; No. 2 (1965), p. 121-124.

20. Dietert, G. Et, Jr., op. cit., , p. 108-110, 166.

21. McLean, D., op. clt., p. 27.

22. Op. clt., p. 179.

23. Friedel, J., "On the Structure of Metall1c Uranium," J. Phys. Chem. Solids 1 (1956), p. 175 .

24. Chiswik, H. H., et al., "Advances in the Physical Metallurgy of Uranium and Its Alloys," Second United Nations International Conference on the Peaceful Uses of Atomic Energy, U.S.A.E.C. Report A/Conf. 15/P/713 U.S.A. (1958).

25. Butcher, B. R., "The Deformation of Aipha Uranium at $450^{\circ} \mathrm{C}$ and $500^{\circ} \mathrm{C}$," U.K.A.E.A. Report A.E.R.E.-R-2898 (1959).

26. Annual Progress Report, "Influence of Minor Components Upon the Constitution and High Temperature Deformation Structure of Uranium," Engineering and Industrial Experiment Station, College of Engineering, University of Florida, Gainesville, Florida (July, 1965).

27. Dietert, G. E., Jr., op. c1t., p. 344 .

28. Taplin, D. M. R., and Martin, J. W., "The Effect of Bmall Additions of Iron and Aluminum on the Tensile Properties of Alpha Uranium," J. of Nuclear Materials 12, No. 1 (1964), p. 50-5.

29. Hanks, G. S., et al., "Effect of Annealing Media on the Mechanical Properties of Uranium," U.S.A.E.C. Report LA-1619, Los Alamos Scientific Laboratory (1956).

30. Marsh, L. L., et a1., "The Effect of Hydrogen on the Tensile Transition In Uranium," U.S. $\bar{A}$. E.C. Report BMI-980, Battelle Memorial Institute (1955). 
31. Dietert, G. E., op. cit., p. 251.

32. Foster, E. L。, Editor, "A Study of the Tensile Fracture and Microstructure of Uranium," U.S.A.E.C. Report BMI-1664, Battelle Memorial Institute (1964) p. 9.

33. Walker, W. W., and Demer, L. J., "The Effect of Loading Duration on Indentation Hardness," Trans. of Met. Soc. AIME 230 (1964), p. 613-4.

34. Merchant, H. D., "Hardness and Creep under Spherical Indentation," Trans. of Met. Soc. AIME 230 (1964), p. 1206-8.

35. Schierding, R. G., and Fergason, L。 A。, "Phase Studles on the Uranium-Iron-Aluminum Ternary System with the klectron Microprobe," Mallinckrodt Chemical Works, Uranium Division (To be published).

36. Tabor, D., The Hardness of Metals, Oxford University Press, Amen House, London $\overline{1951), p} \cdot \overline{7}-\overline{11}$ 。

37. McDone11, W. R., and Angerman, C. L., "The Effect of Microstructure on Cavitational Swelling of Dílute Uranium Alloys," U.S.A.E.C. Report CONF-650904-4 (1965). 


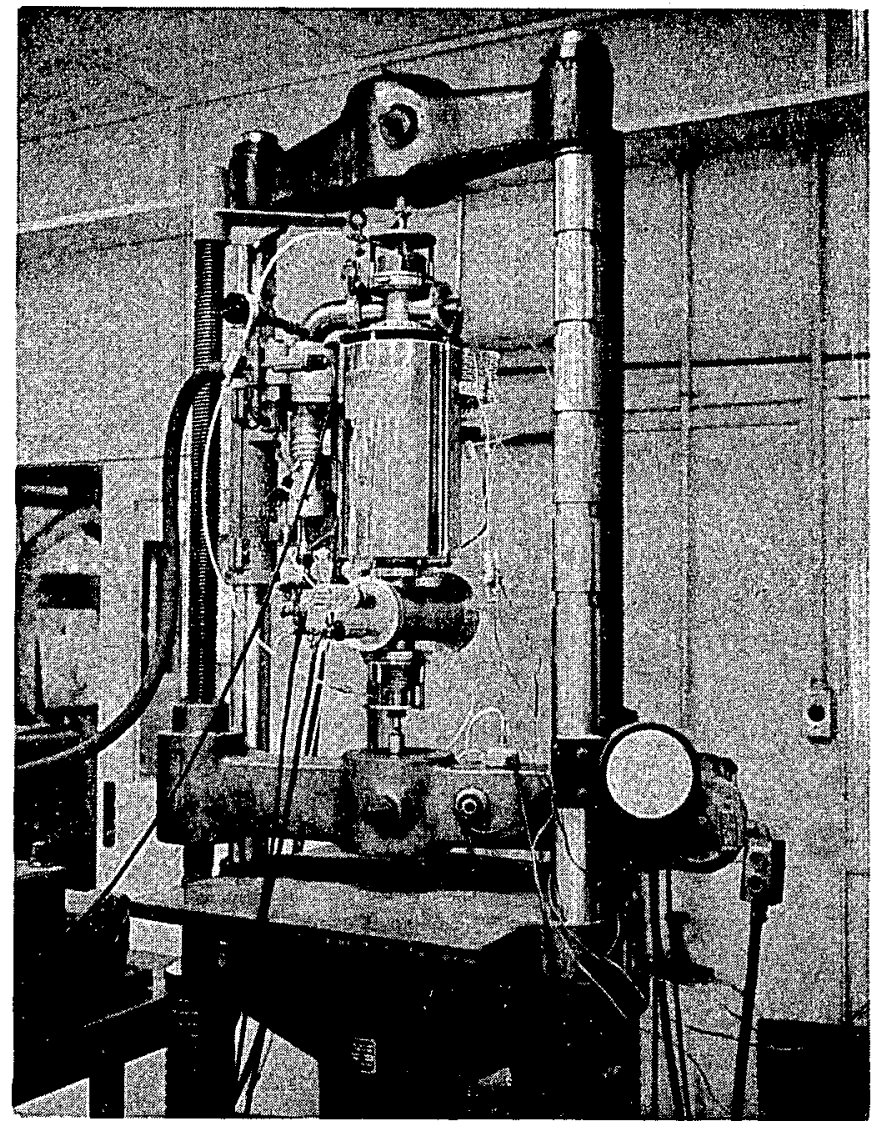

Figure 1. High-Temperature Vacuum Furnace and Diffusion Pump Positioned between the Crossheads of the Tensile Testing Machine. 


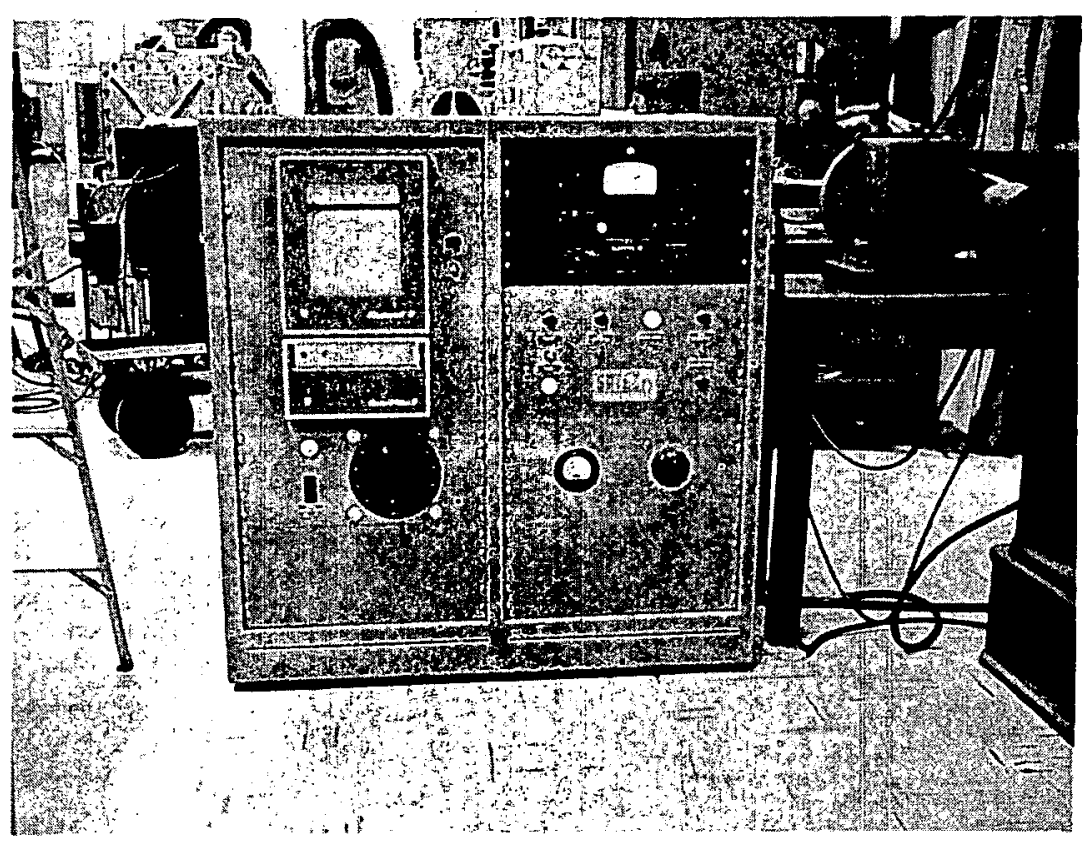

Figure 2. The Support-Equipment Cabinet Containing Vacuum and Temperature Controls for the Elevated-Temperature Tensile Testing Equipment. 


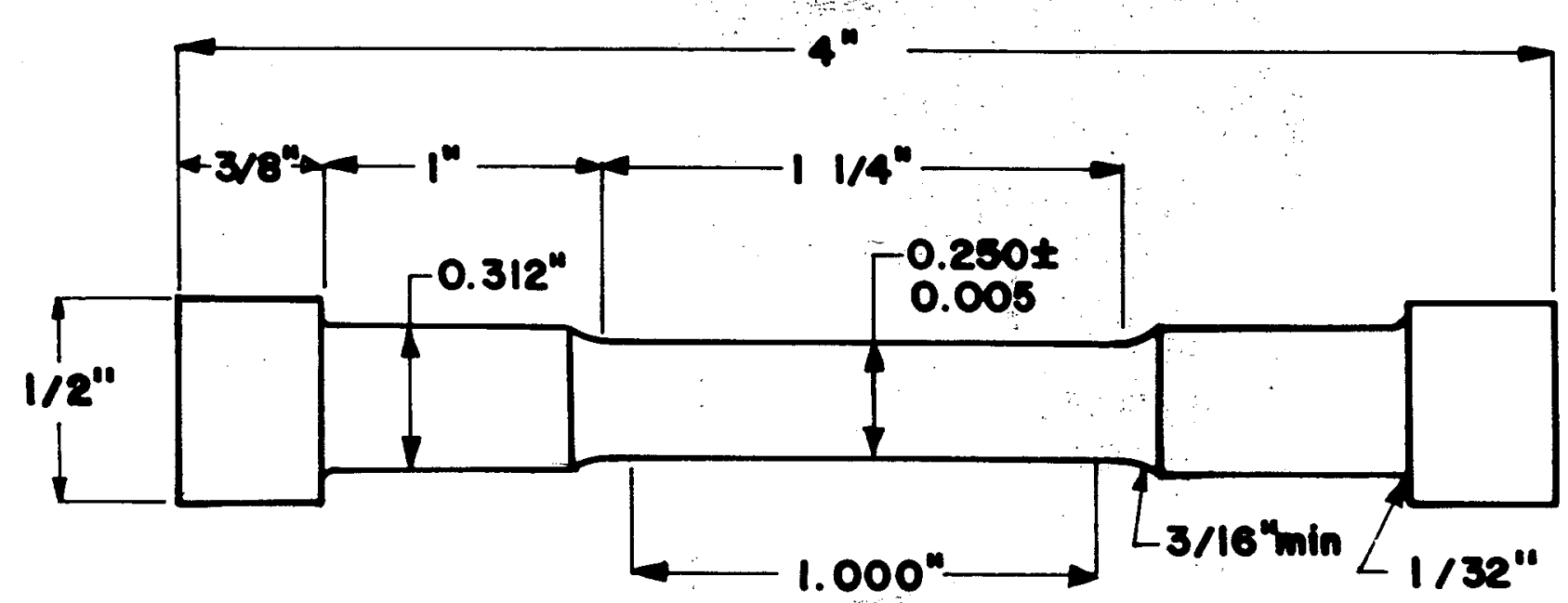

Figure 3. Dimensions of Shouldered-End Tensile Test Specimens for Elevated-Temperature Tensile Testing of Uranium. 


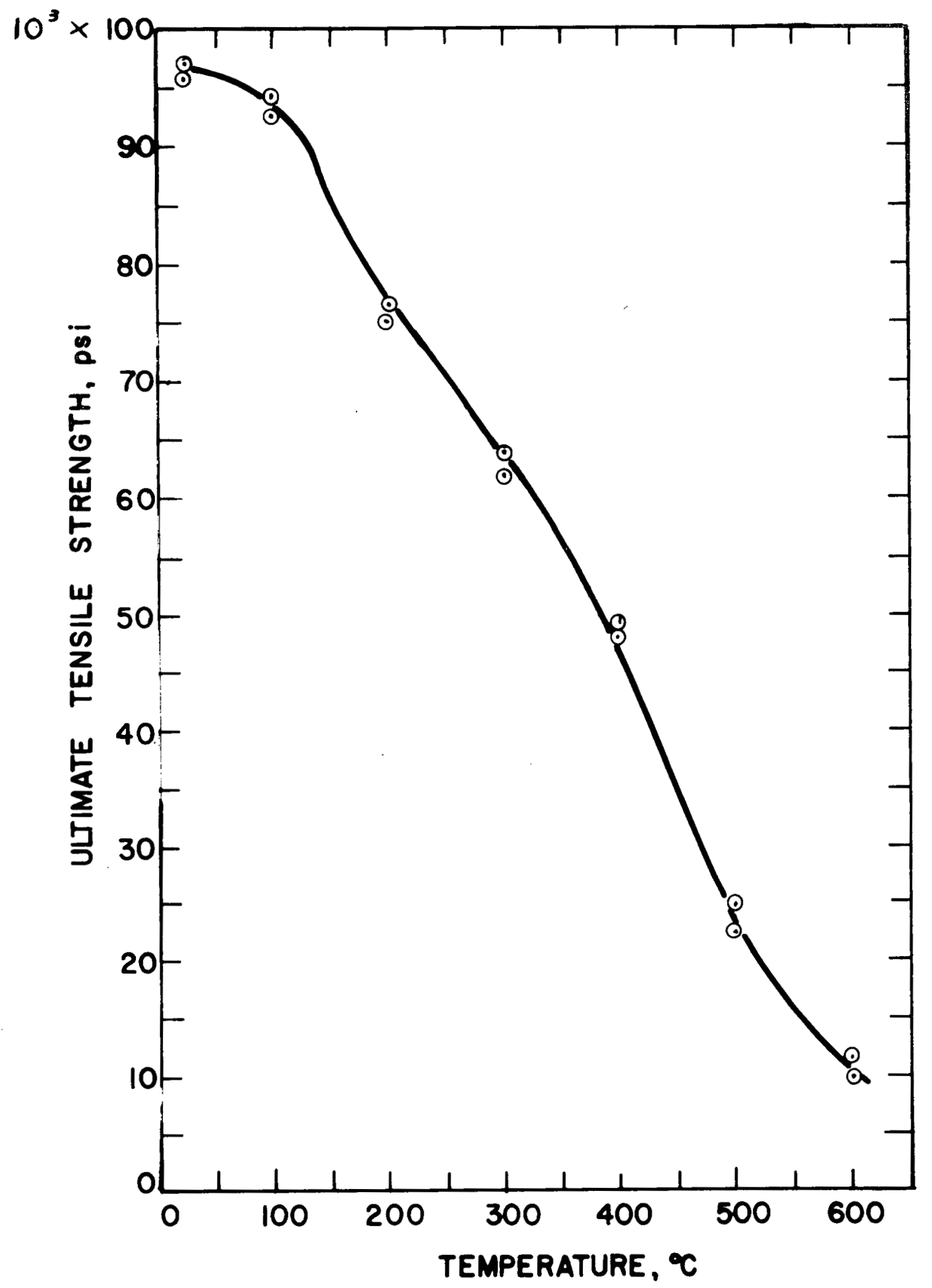

Figure 4. The Effect of Temperature on the Ultimate Tensile Strength of a Centrifugally Cast, Beta Heat-Treated, 175-PPM-Fe, 340-PPN-Si Uranium Alloy. 


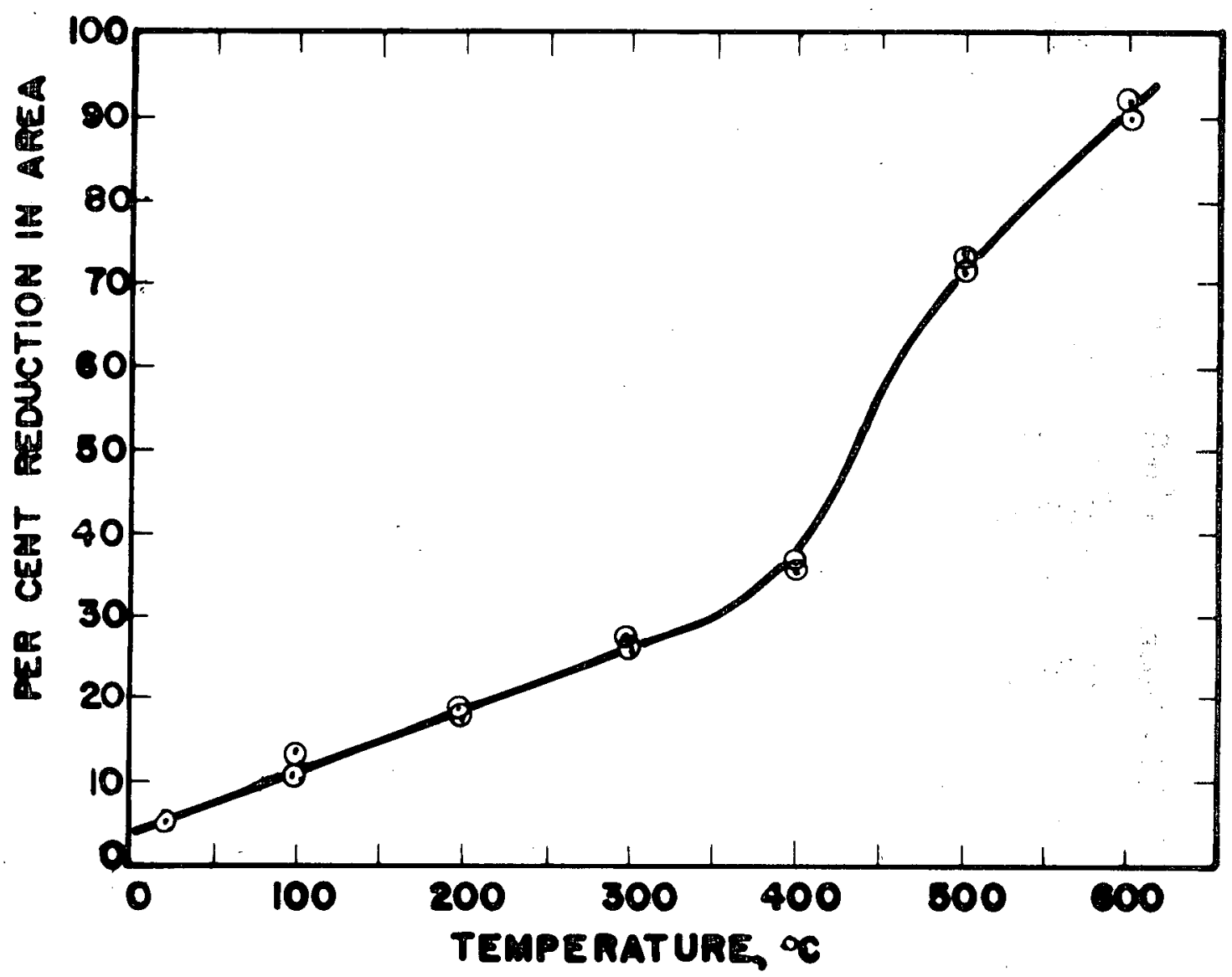

Figure 5. The Effect of Temperature on the Percent Reduction in Area of a Centrifugally Cast, Beta Heat-Treated, 175-PPM-Fe, 340-PPM-Si

Uranium Alloy. 


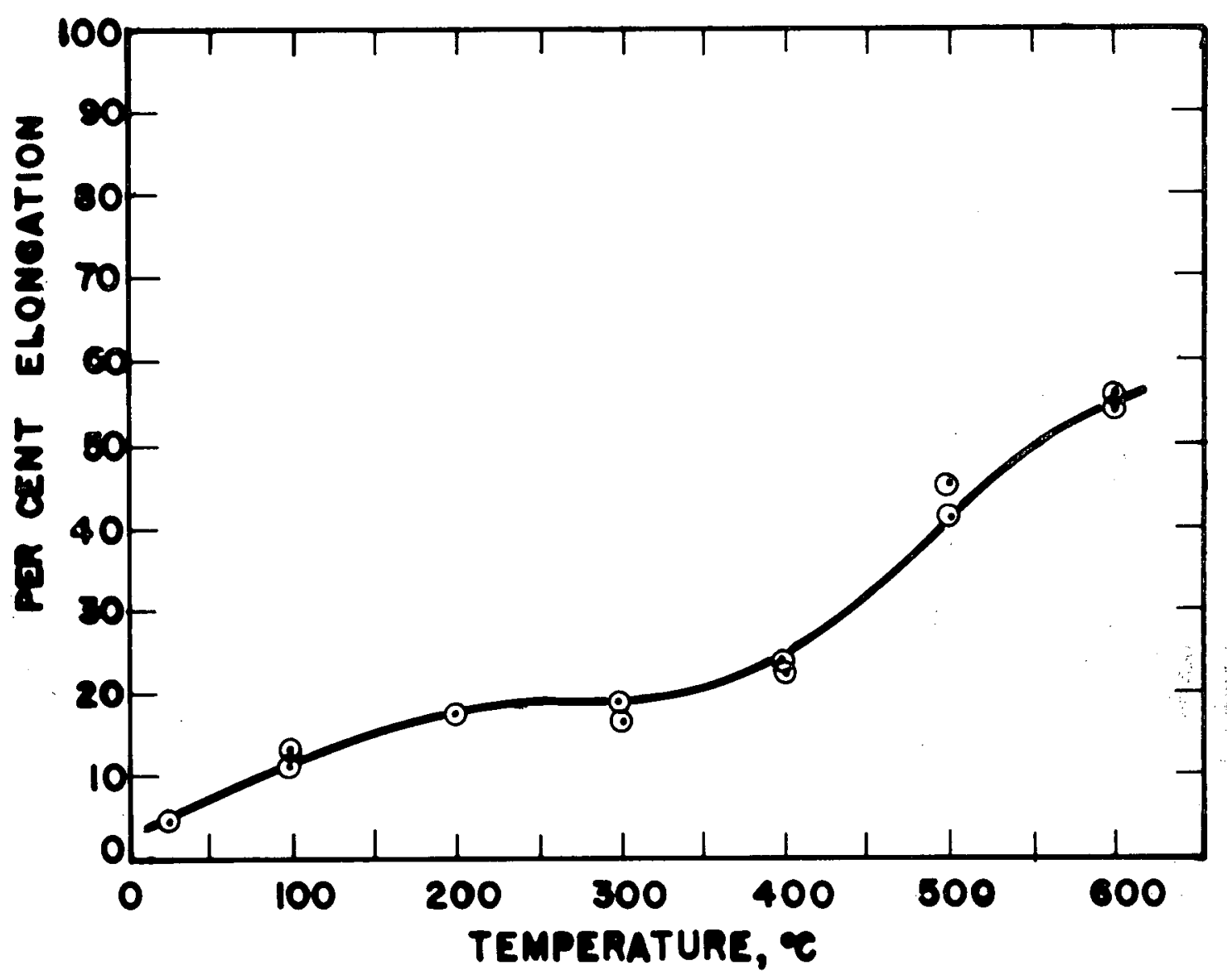

Figure 6. The Effect of Temperature on the Percent Elongation of a Centrifugally Cast, Beta Heat-Treated, 175-PPM-Fe, 340-PPM-Si Uranium Alloy. 


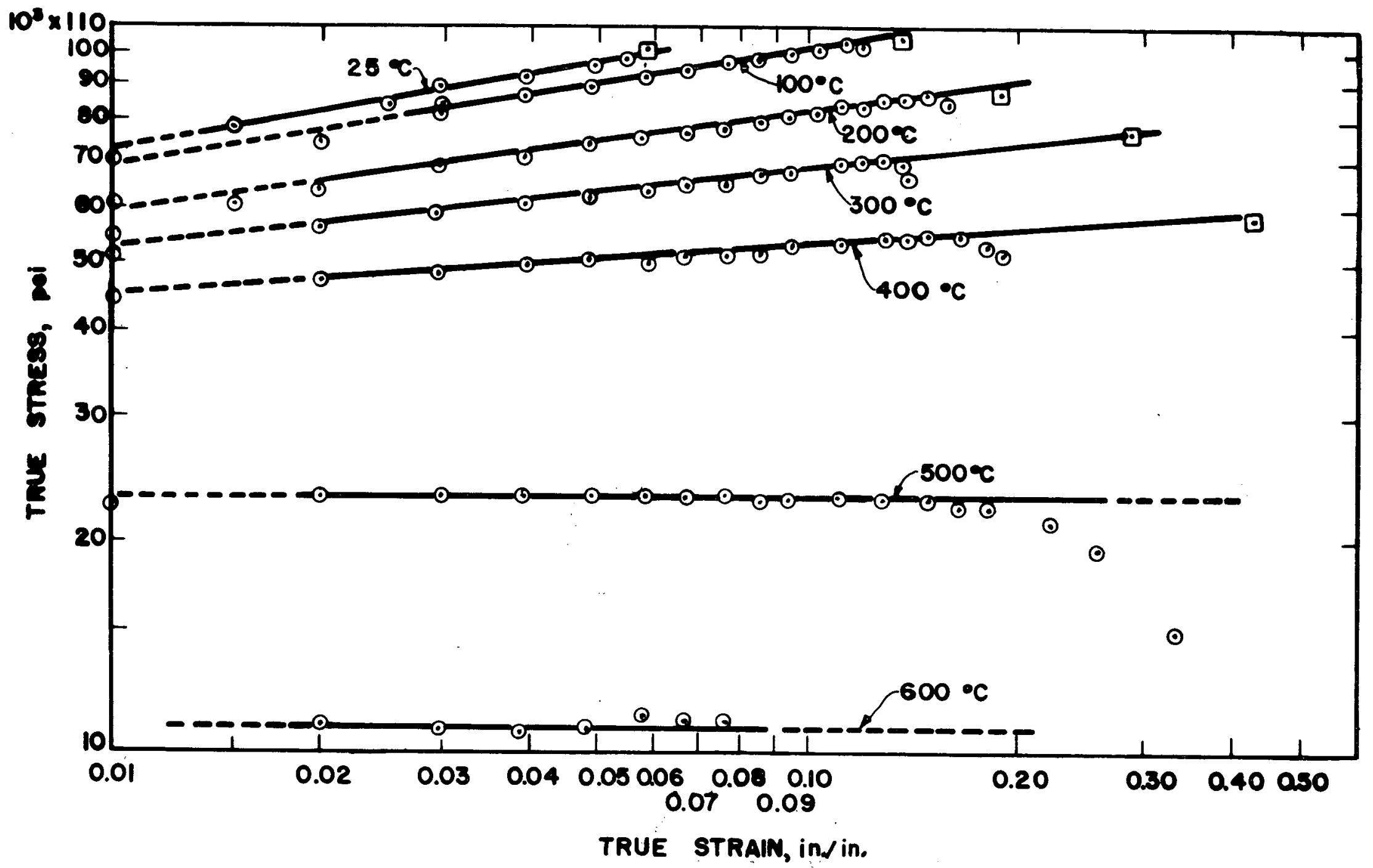

Figure 7. The Effect of Temperature on the True Stress-True Strain Curves of a Centrifugally Cast, Beta Heat-Treated, 175-PPM-Fe, 340-PPM-Si Uranium Alloy. 


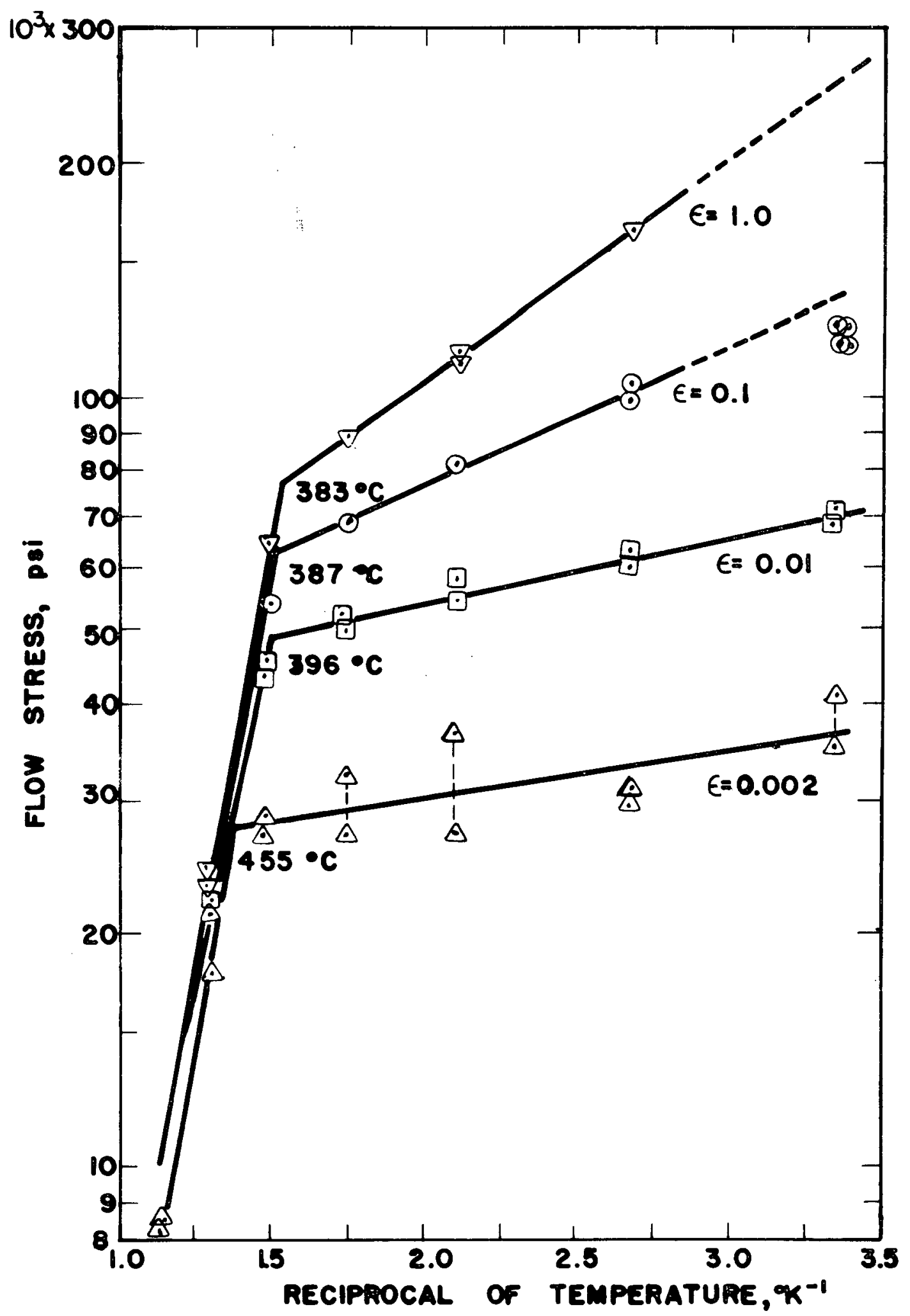

Figure 8. The Effect of Temperature on the Flow Stress Necessary to Produce a Particular Level of Strain in a Centrifugally Cast, Beta Heat-Treated, 175-PPM-Fe, 340-PPM-Si Uranium Alloy. 


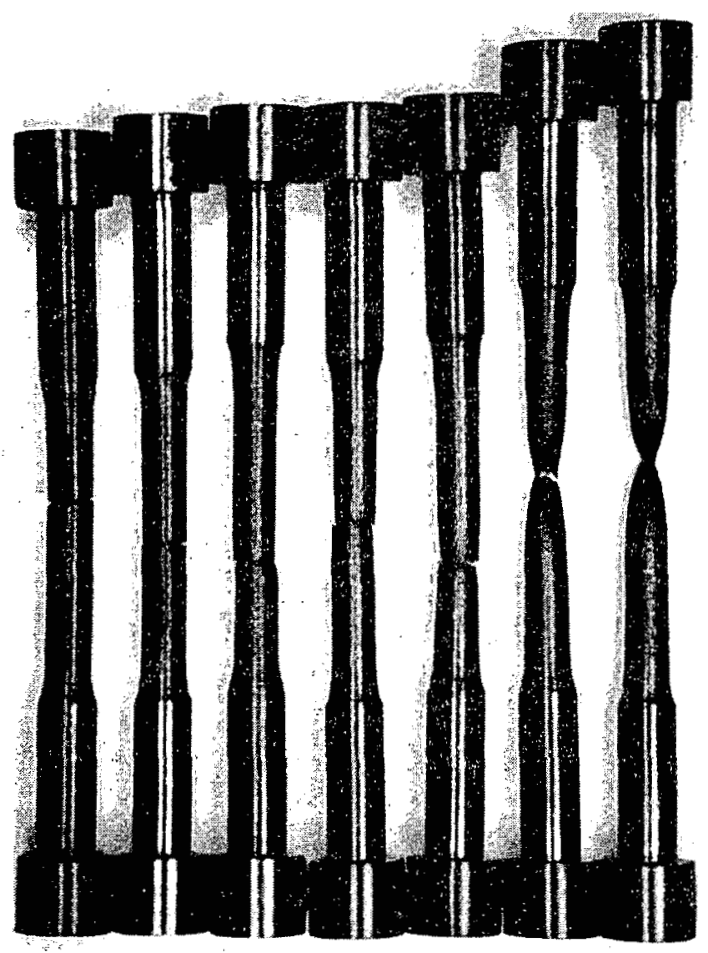

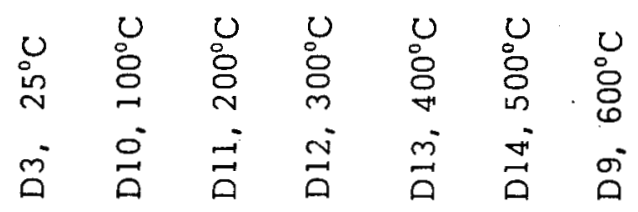

Figure 9. Fractured Tensile Samples of the Dilute Uranium Alloy Investigated after Tensile Testing at Various Alpha Temperatures. 


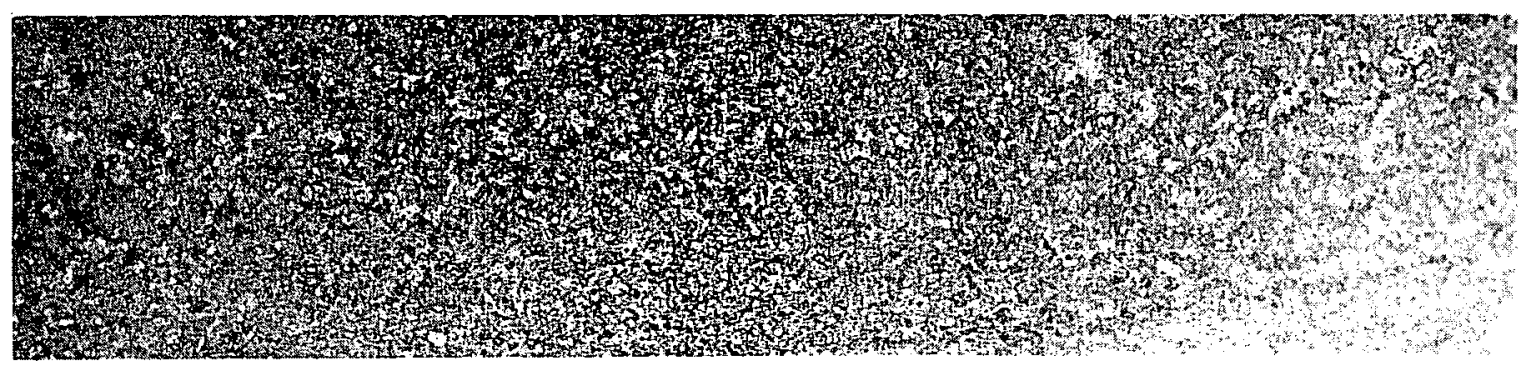

(a) Longitudinal section - casting in-gate to right.

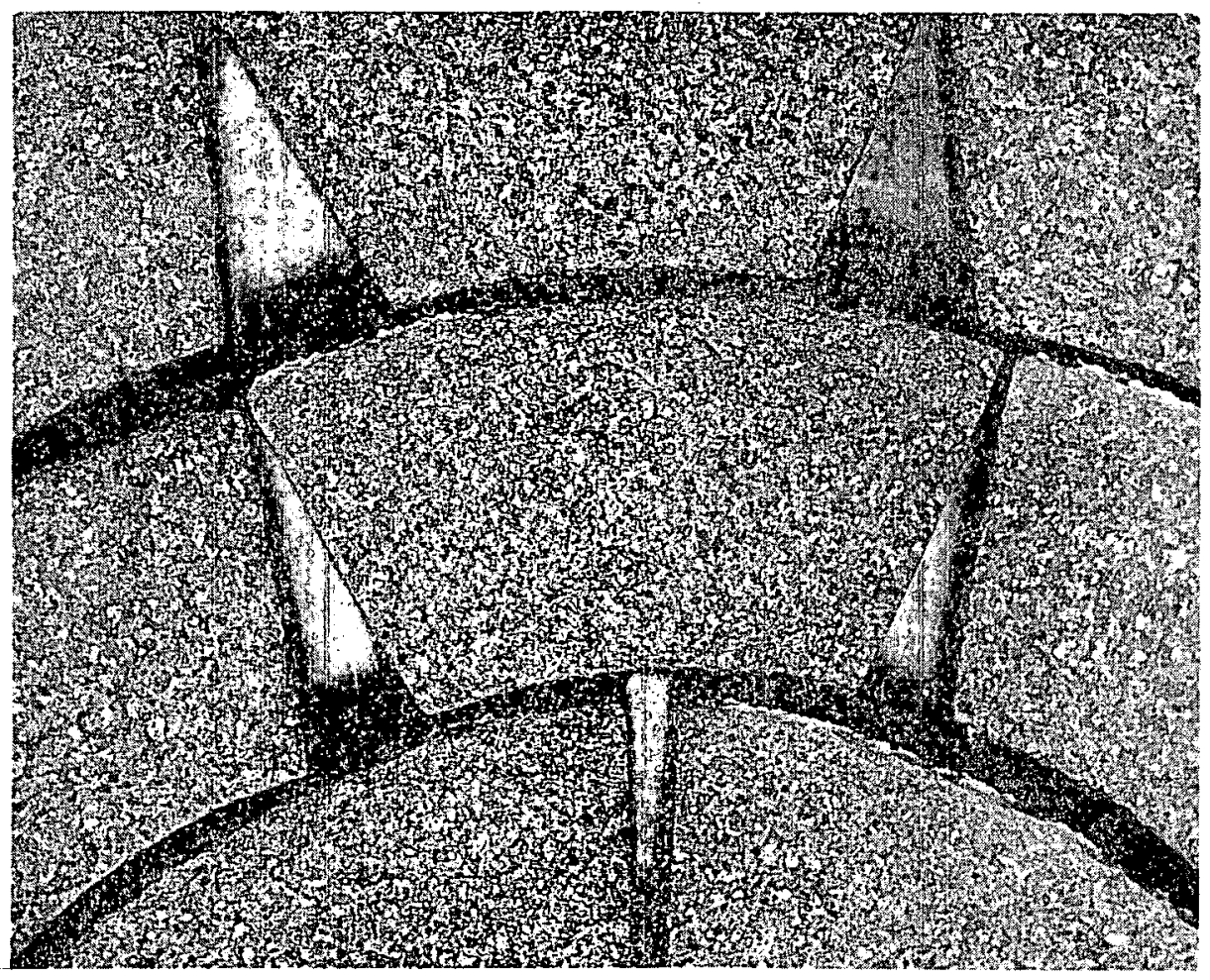

(b) Transverse Sections - upper left corner section is from top of the tube cross-section; succeeding sections taken $1 / 2$ inch apart are shown left to right with the tube bottom section at lower right hand in the figure.

Figure 10. The Macro Grain Structure of the Centrifugally Cast Tube from which the Tensile Samples were Machined. FEDC Grain Size No. D6. 3X. 


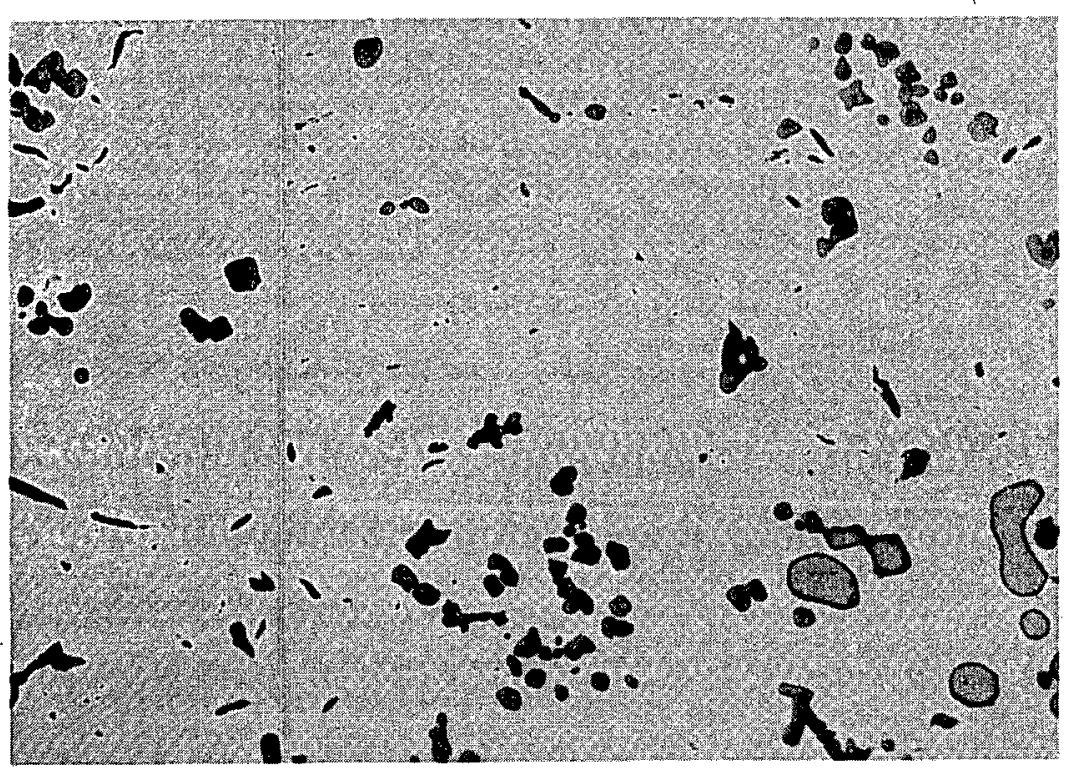

Figure 11. Distribution of Precipitates and Inclusions in the Centrifugally Cast Tube. $500 X$. Uranium hydrides appear as long, thin particles; angular particles are uranium carbides. 


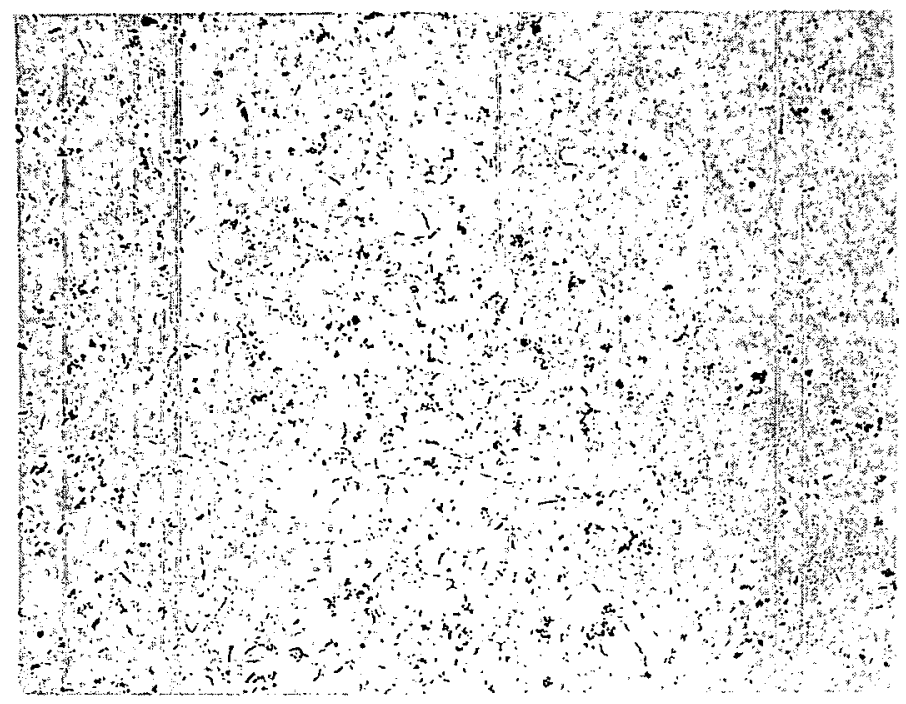

(a) Unstrained.

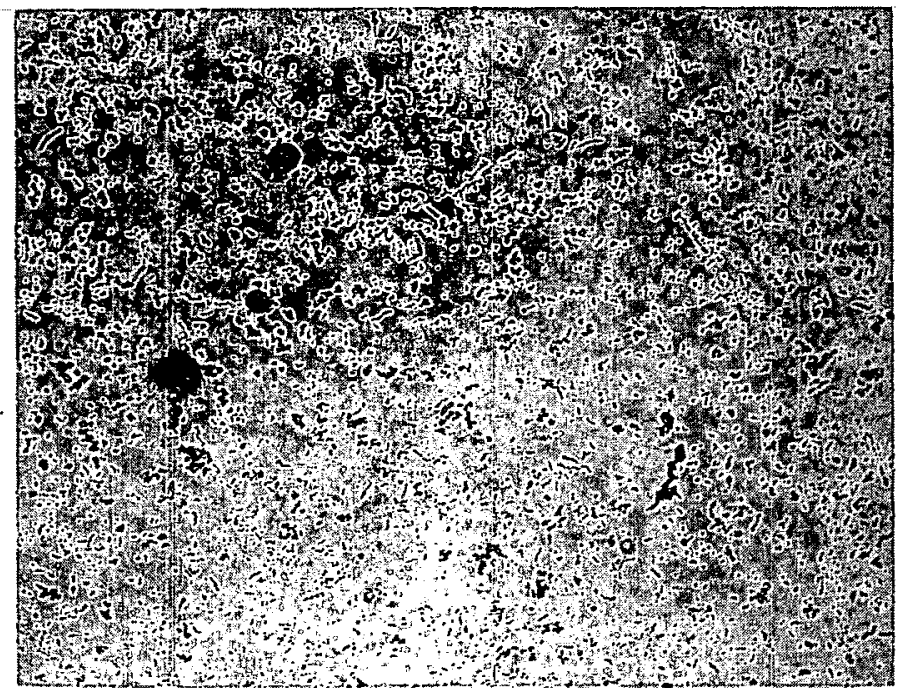

(b) Tested at $25^{\circ} \mathrm{C}$.

Figure 12. Microstructures of Tensile Test Specimens Adjacent to the Fractured Surface. In each case, tensile axis is horizontal and the fracture is at the left. $75 \mathrm{X}$. 


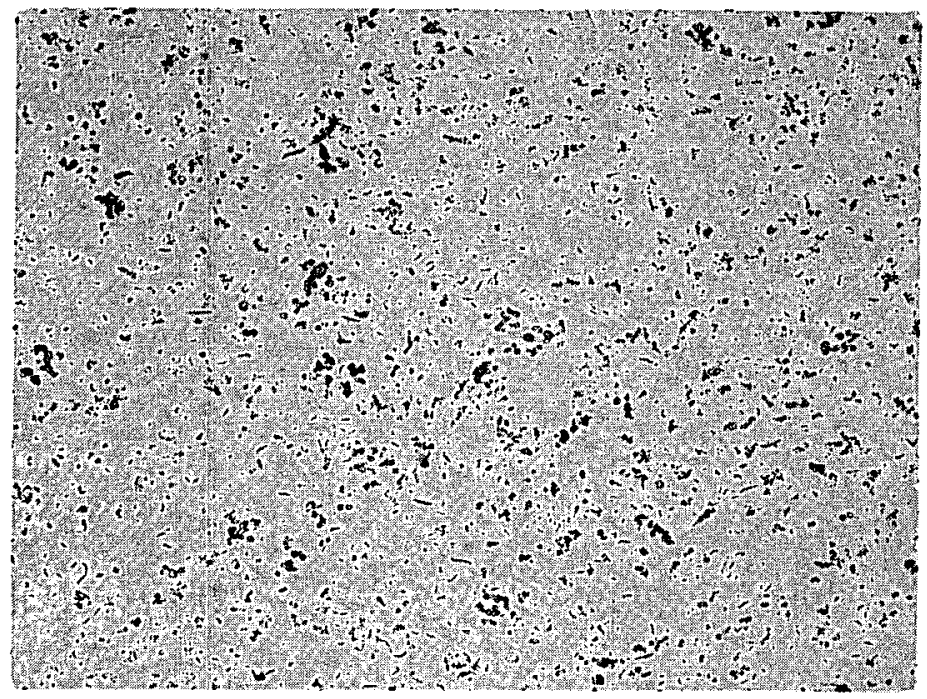

(c) Tested at $100^{\circ} \mathrm{C}$.

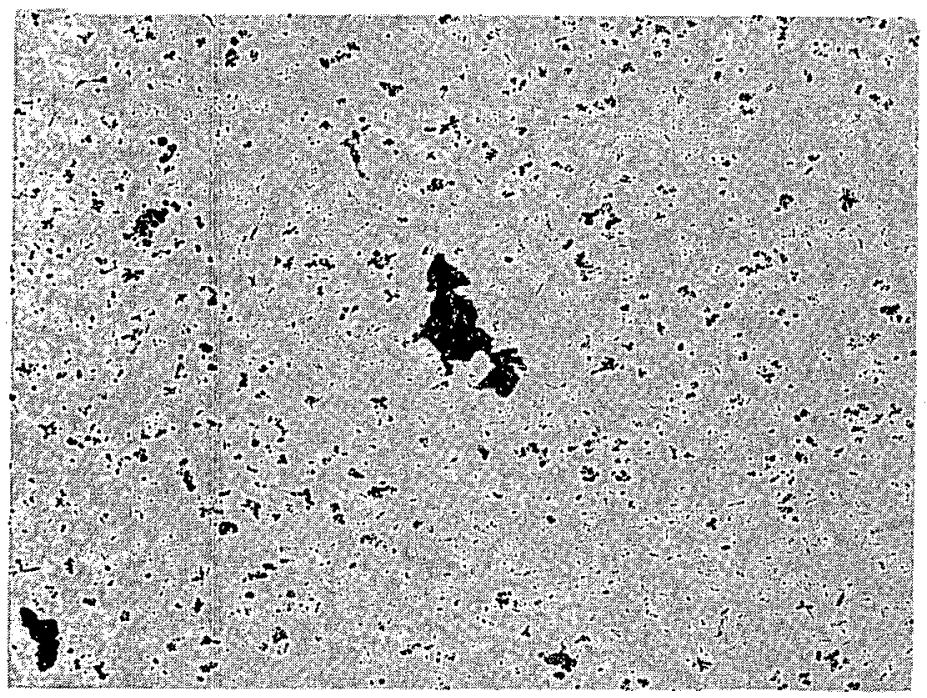

(d) Tested at $200^{\circ} \mathrm{C}$.

Figure 12 (Continued). 


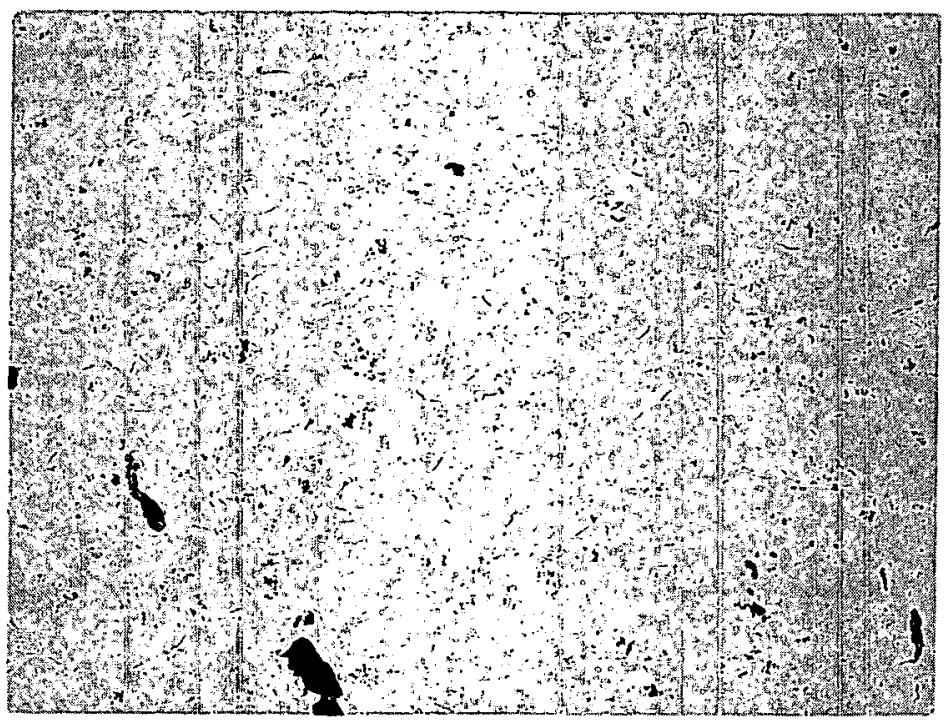

(e) Tested at $300^{\circ} \mathrm{C}$.

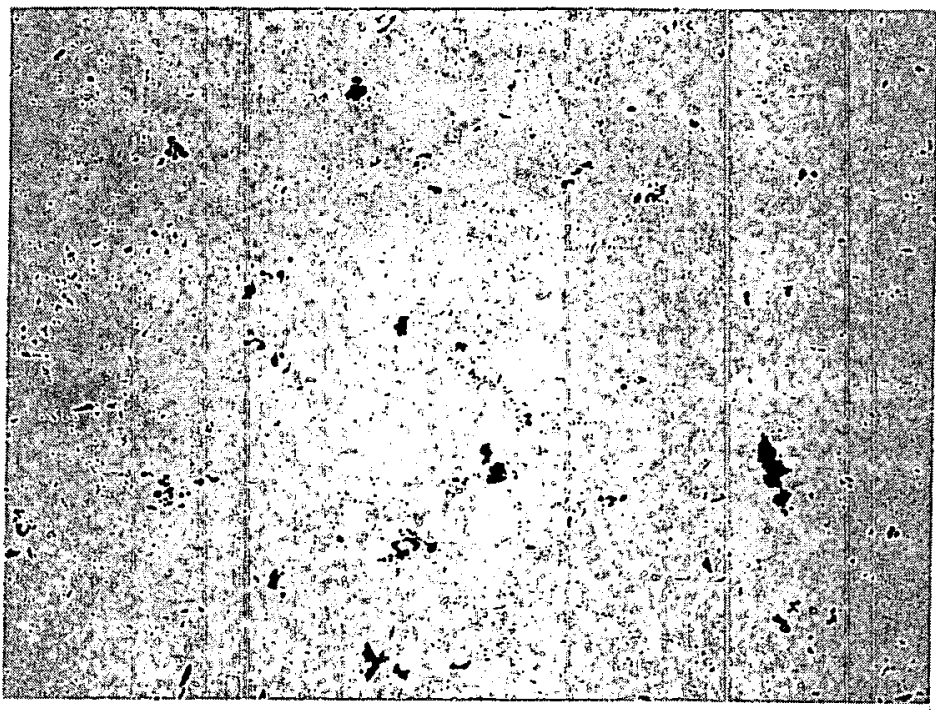

(f) Tested at $400^{\circ} \mathrm{C}$.

Figure 12 (Continued). 


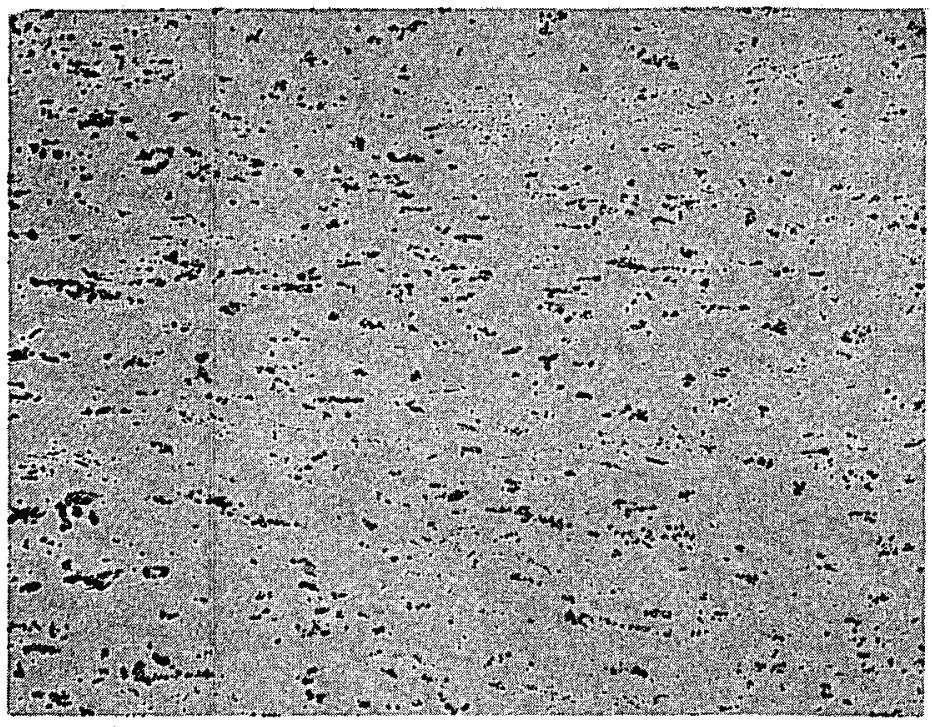

(g) Tested at $500^{\circ} \mathrm{C}$.

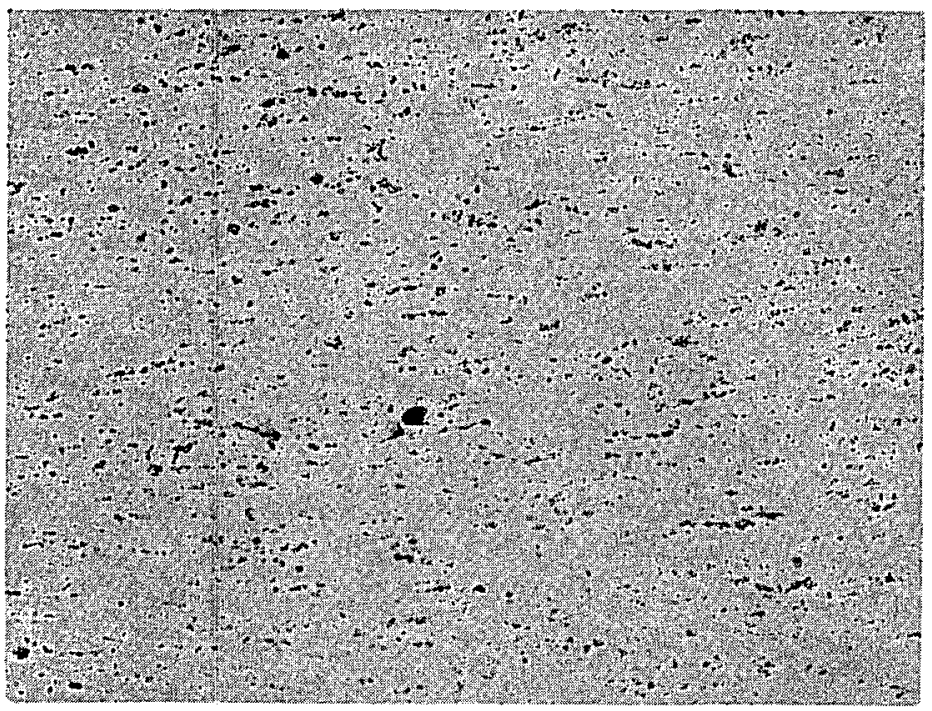

(h) Tested at $600^{\circ} \mathrm{C}$.

Figure 12 (Continued). 


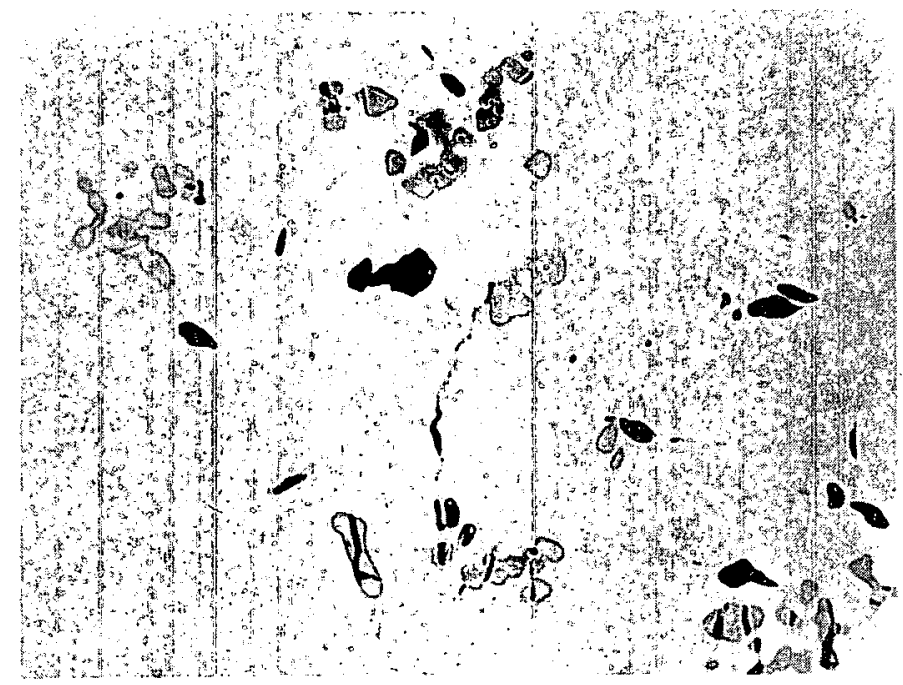

(a) Tested at $25^{\circ} \mathrm{C}$.

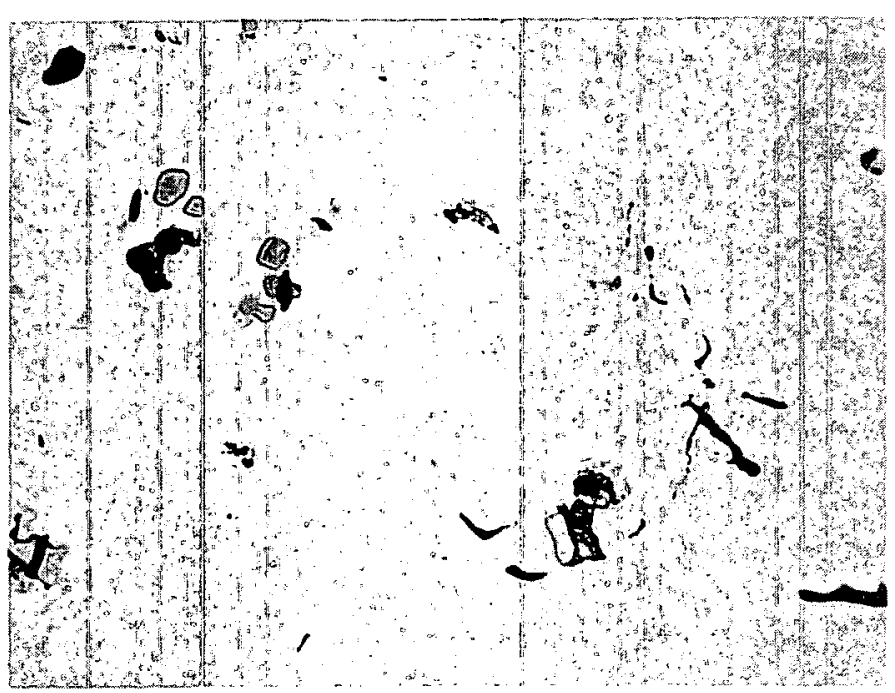

(b) Tested at $100^{\circ} \mathrm{C}$.

Figure 13. Micro-Cracks Generated at Inclusions during Tensile Testing. Tensile axis is horizontal and fracture is at left. $750 x$. 


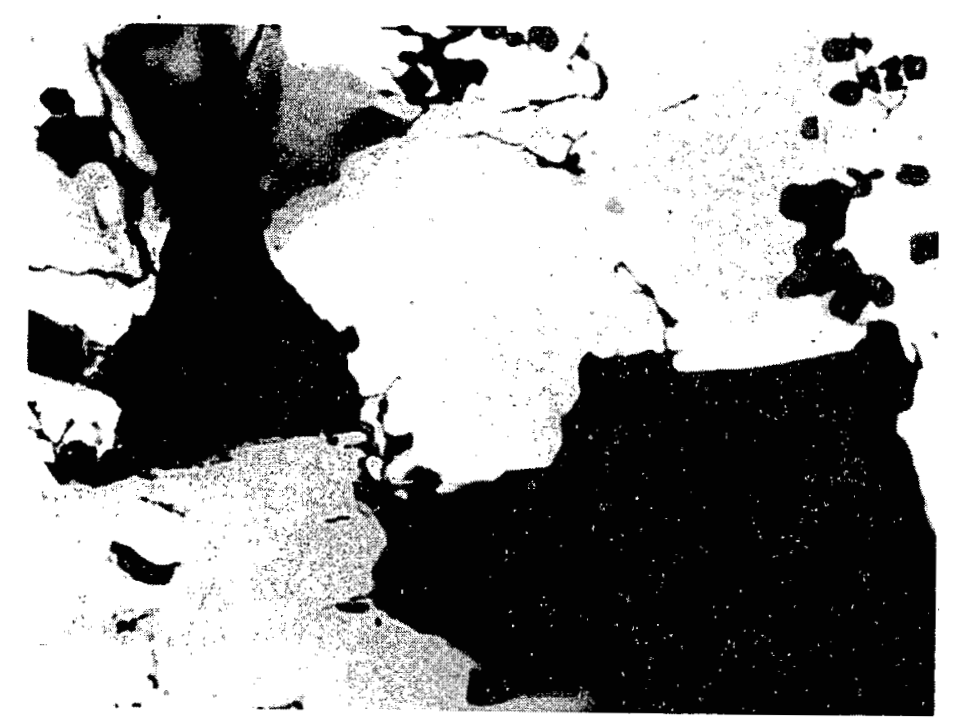

(c) Tested at $200^{\circ} \mathrm{C}$.

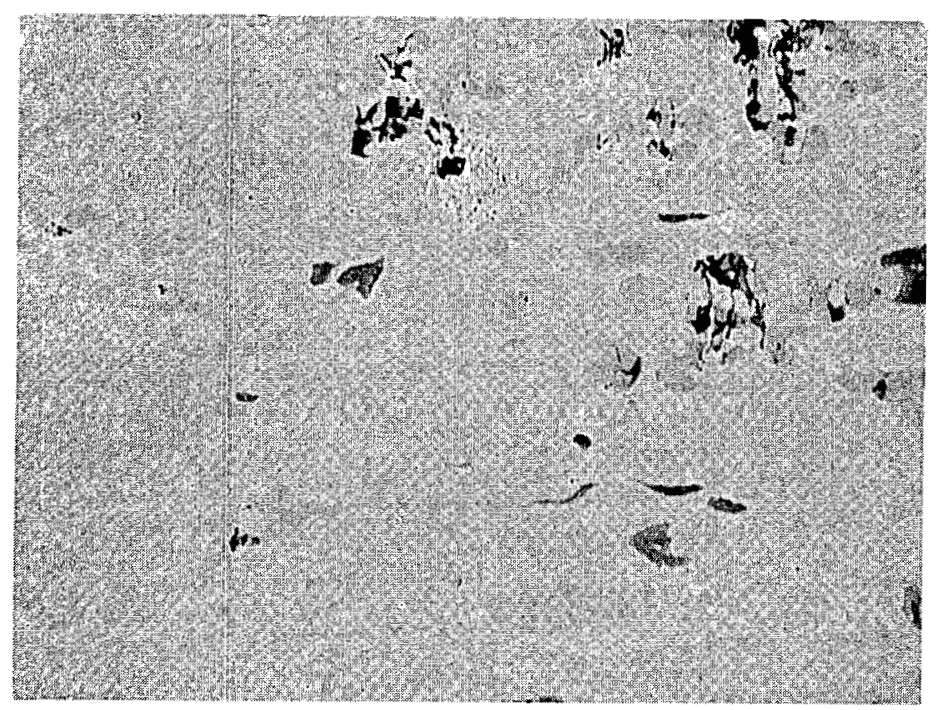

(d) Tested at $300^{\circ} \mathrm{C}$.

Figure 13 (Continued). 


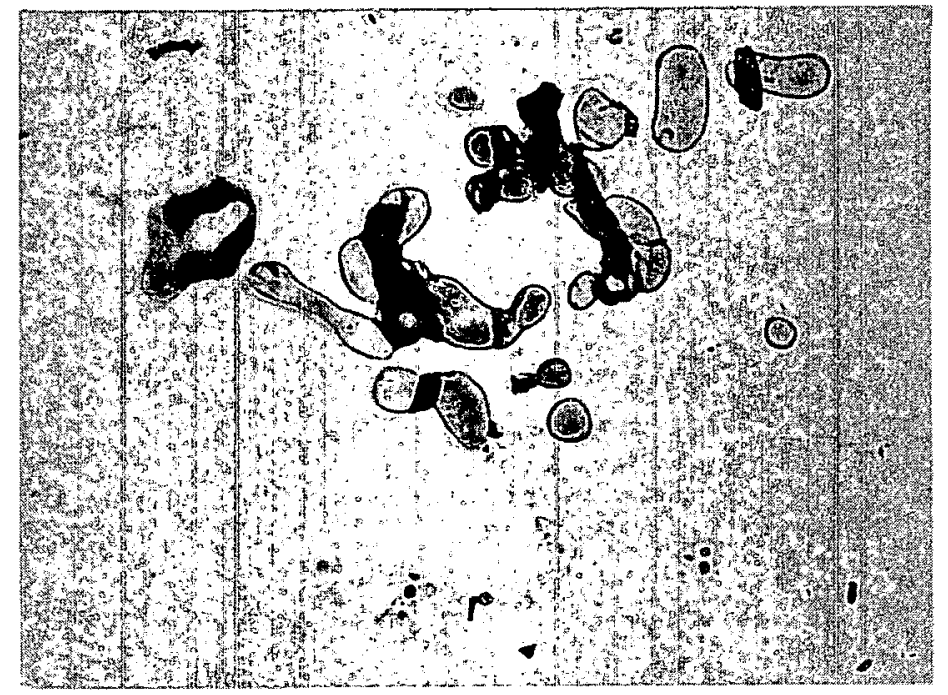

(e) Tested at $400^{\circ} \mathrm{C}$.

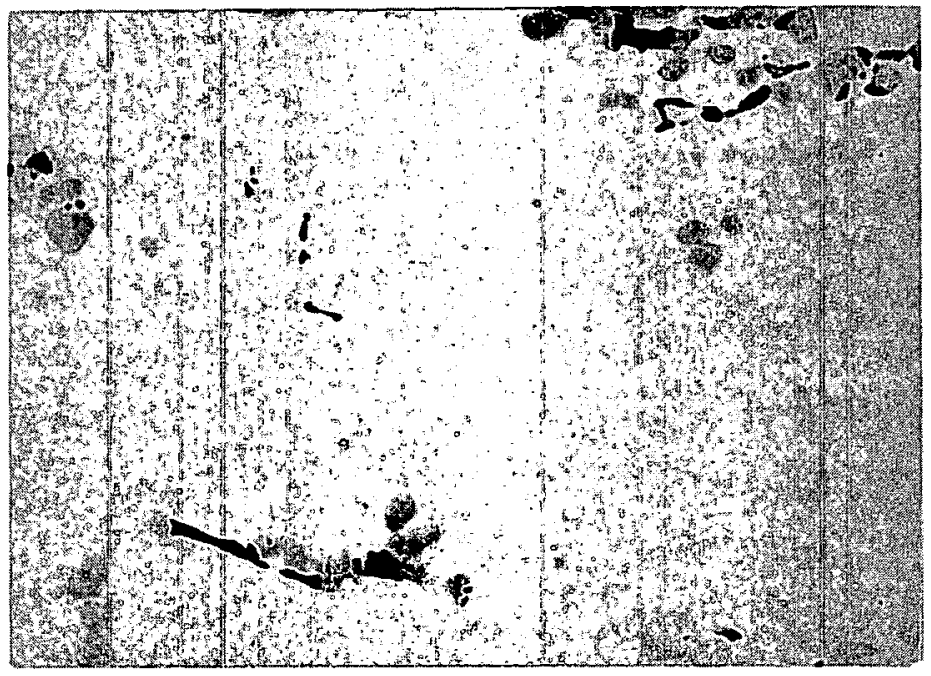

(f) Tested at $500^{\circ} \mathrm{C}$.

Figure 13 (Continued). 


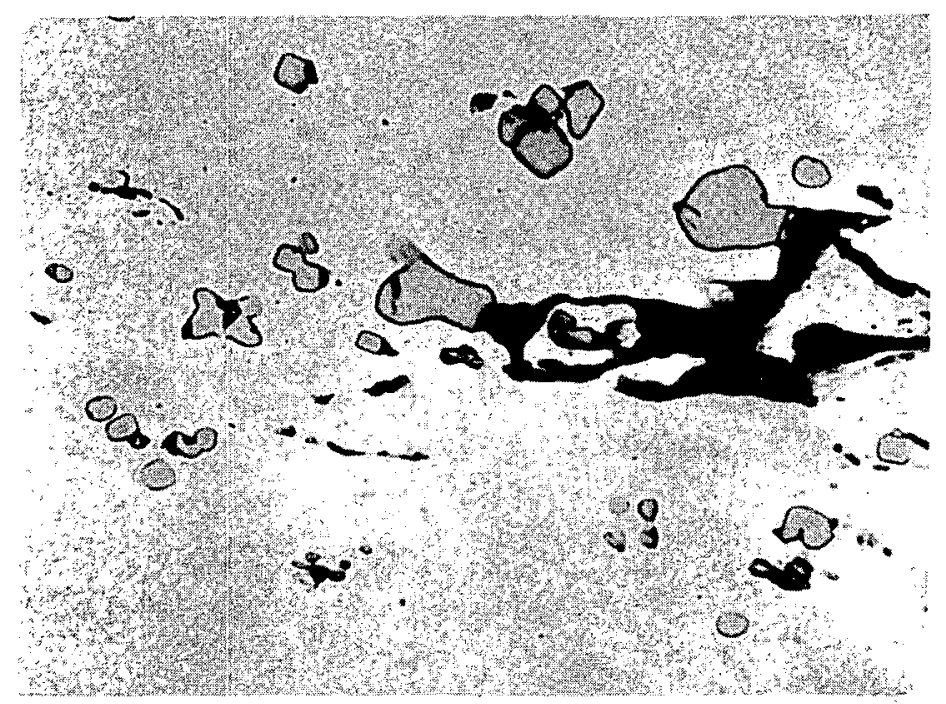

(g) Tested at $600^{\circ} \mathrm{C}$.

Figure 13 (Continued). 


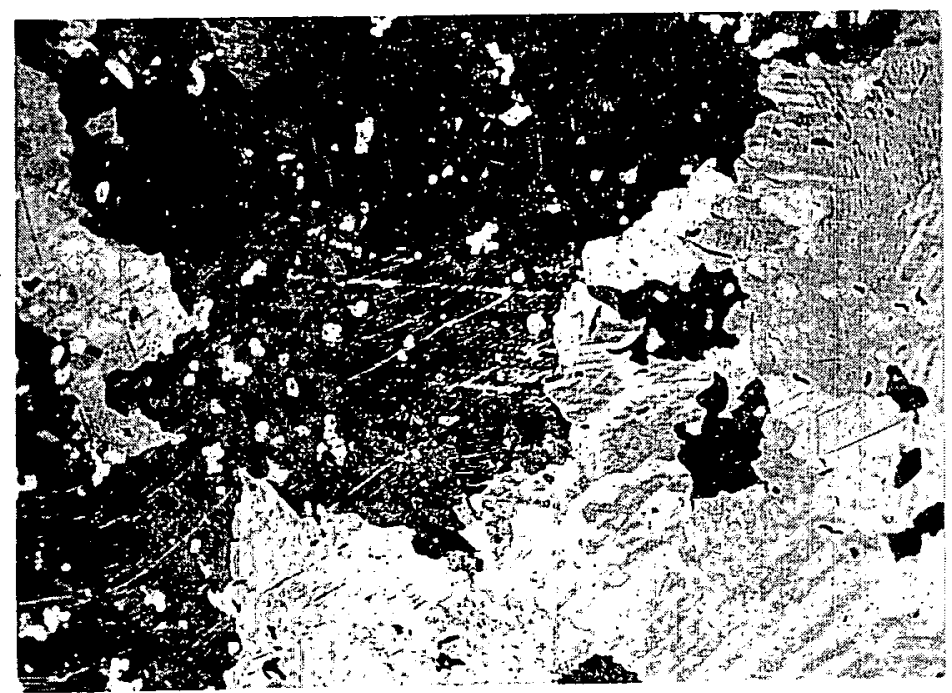

(a) Unstrained.

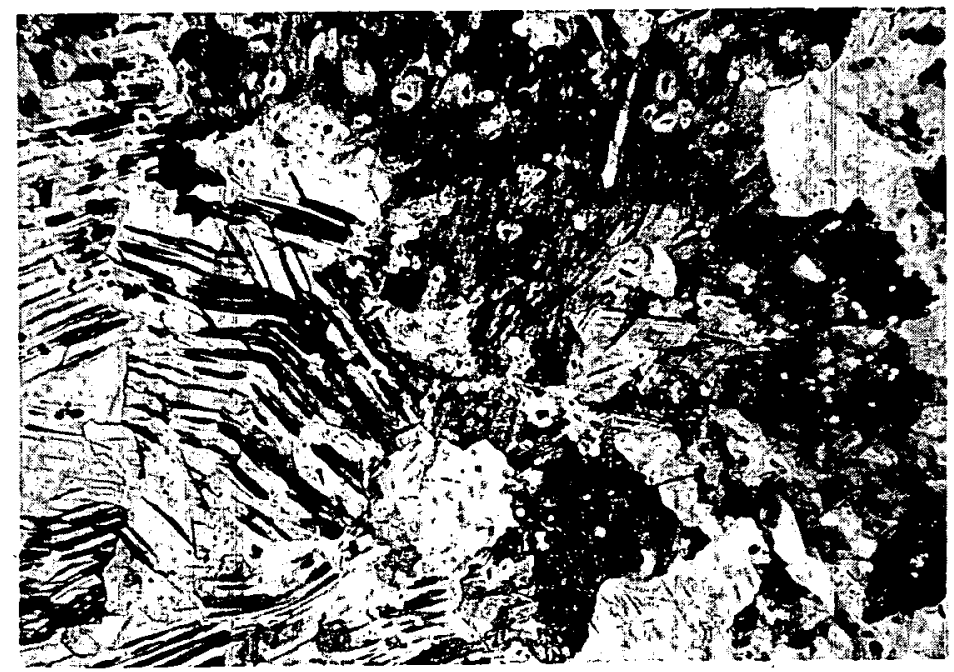

(b) Tested at $25^{\circ} \mathrm{C}$.

Figure 14. Longitudinal Microstructure Adjacent to Fracture of Tensile Test Specimens. Fracture surface at left. $200 \mathrm{X}$. 


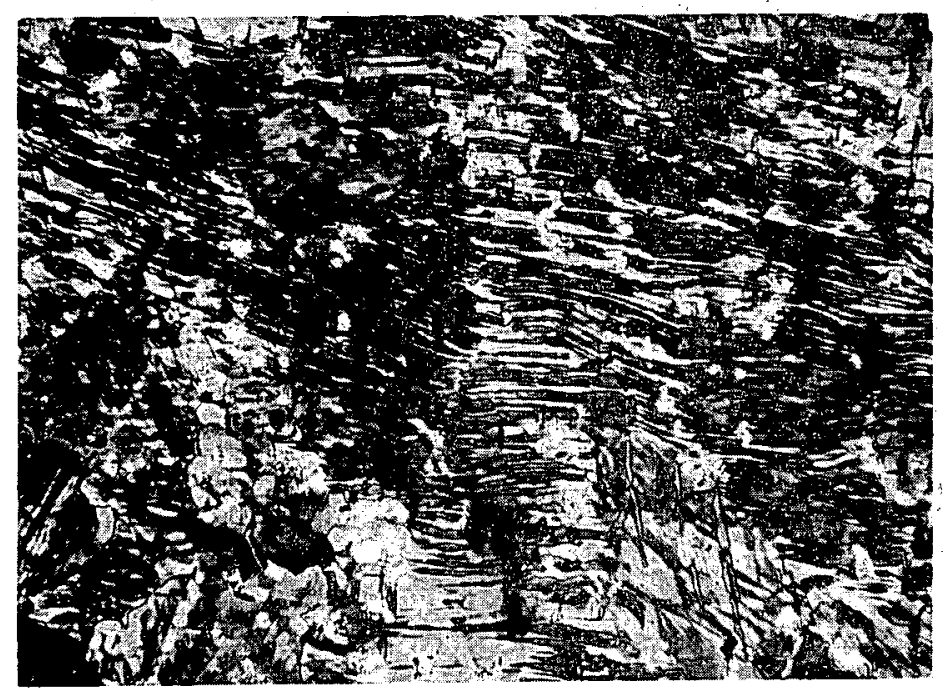

(c) Tested at $100^{\circ} \mathrm{C}$.

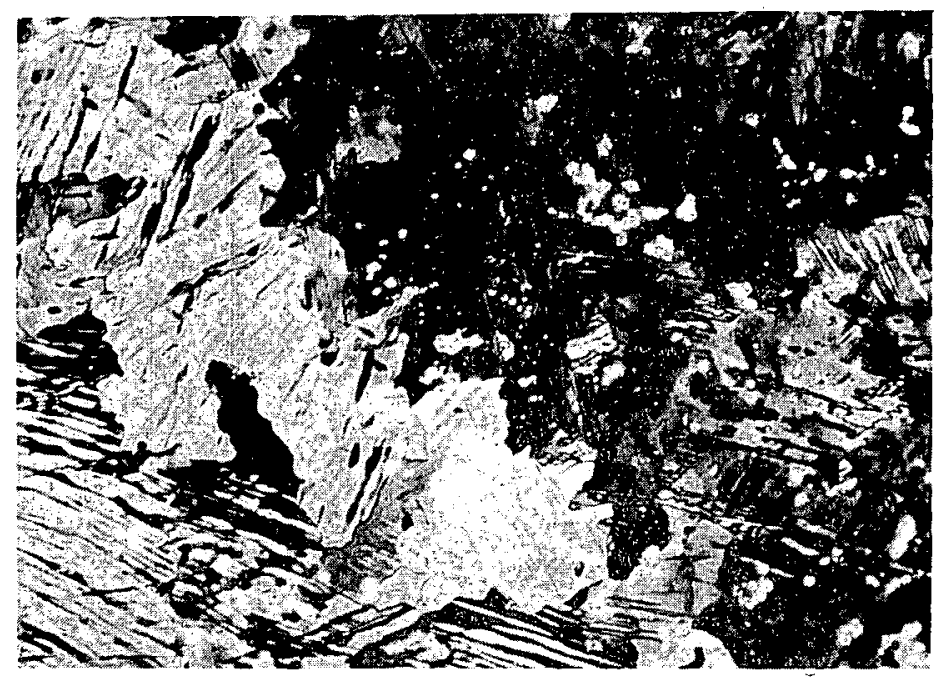

(d) Tested at $200^{\circ} \mathrm{C}$.

Figure 14 (Continued). 


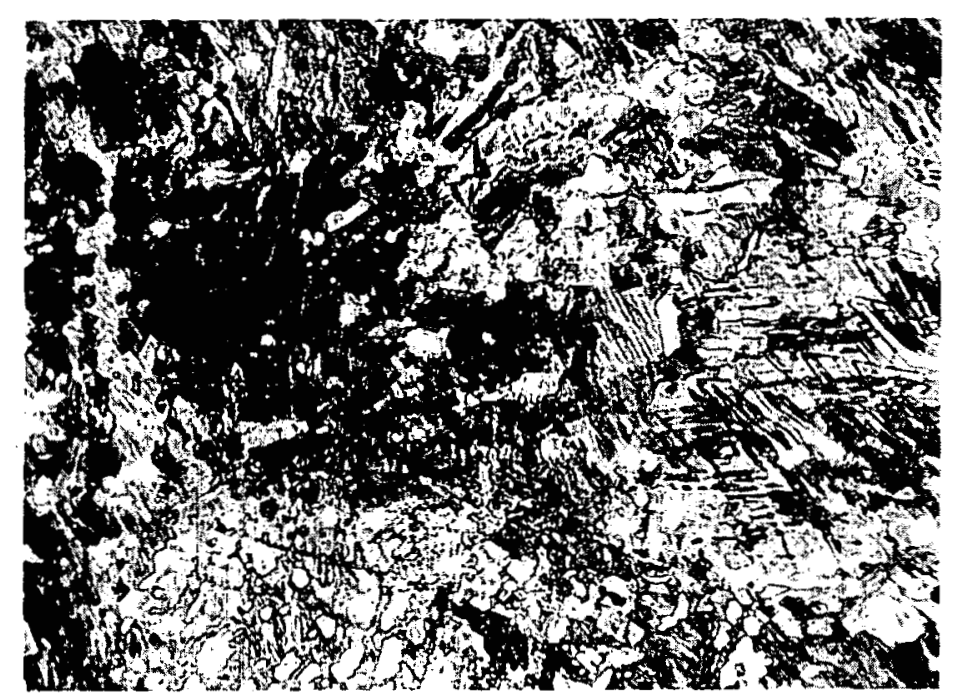

(e) Tested at $300^{\circ} \mathrm{C}$.

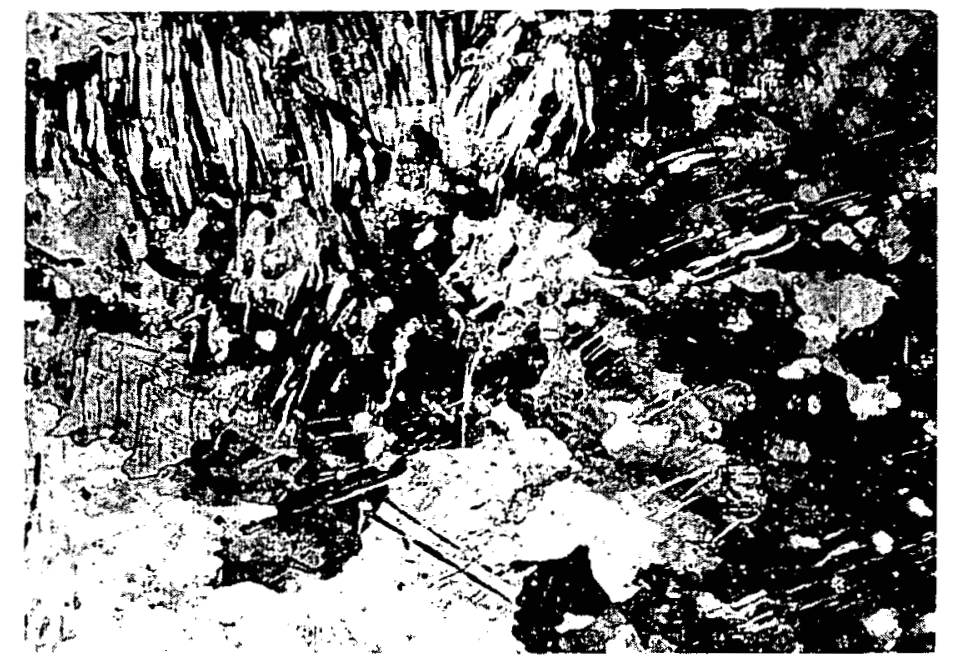

(f) Tested at $400^{\circ} \mathrm{C}$.

Figure 14 (Continued). 


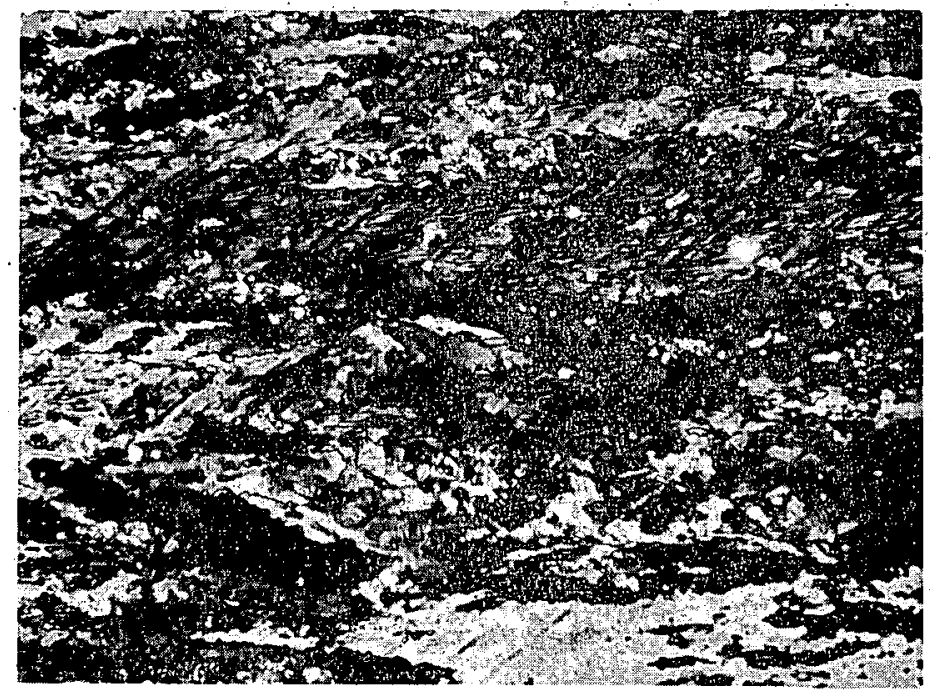

(g) Tested at $500^{\circ} \mathrm{C}$.

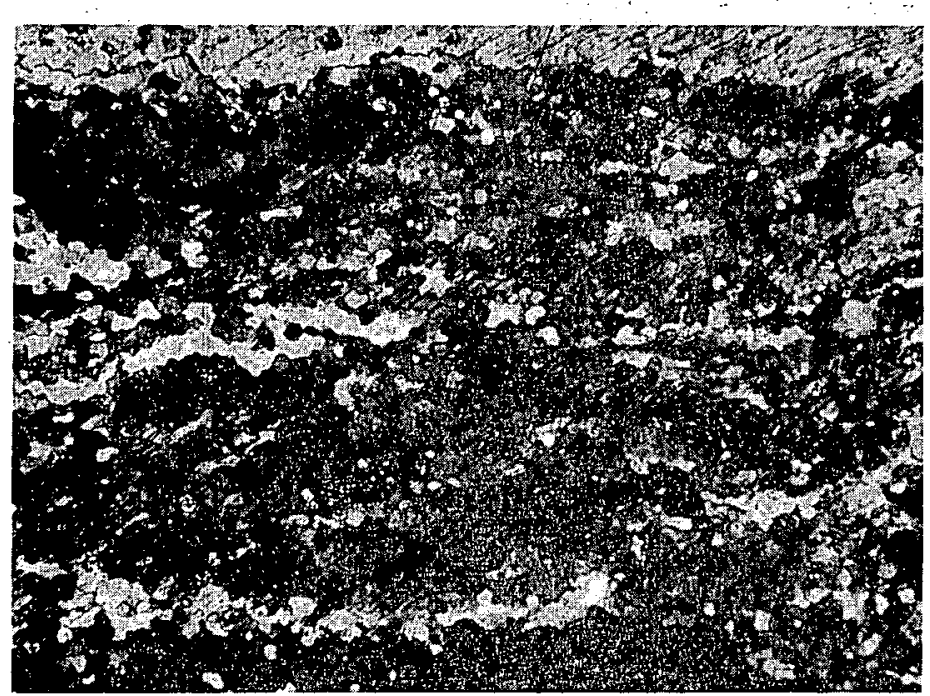

(h) Tested at $600^{\circ} \mathrm{C}$.

Figure 14 (Continued). 


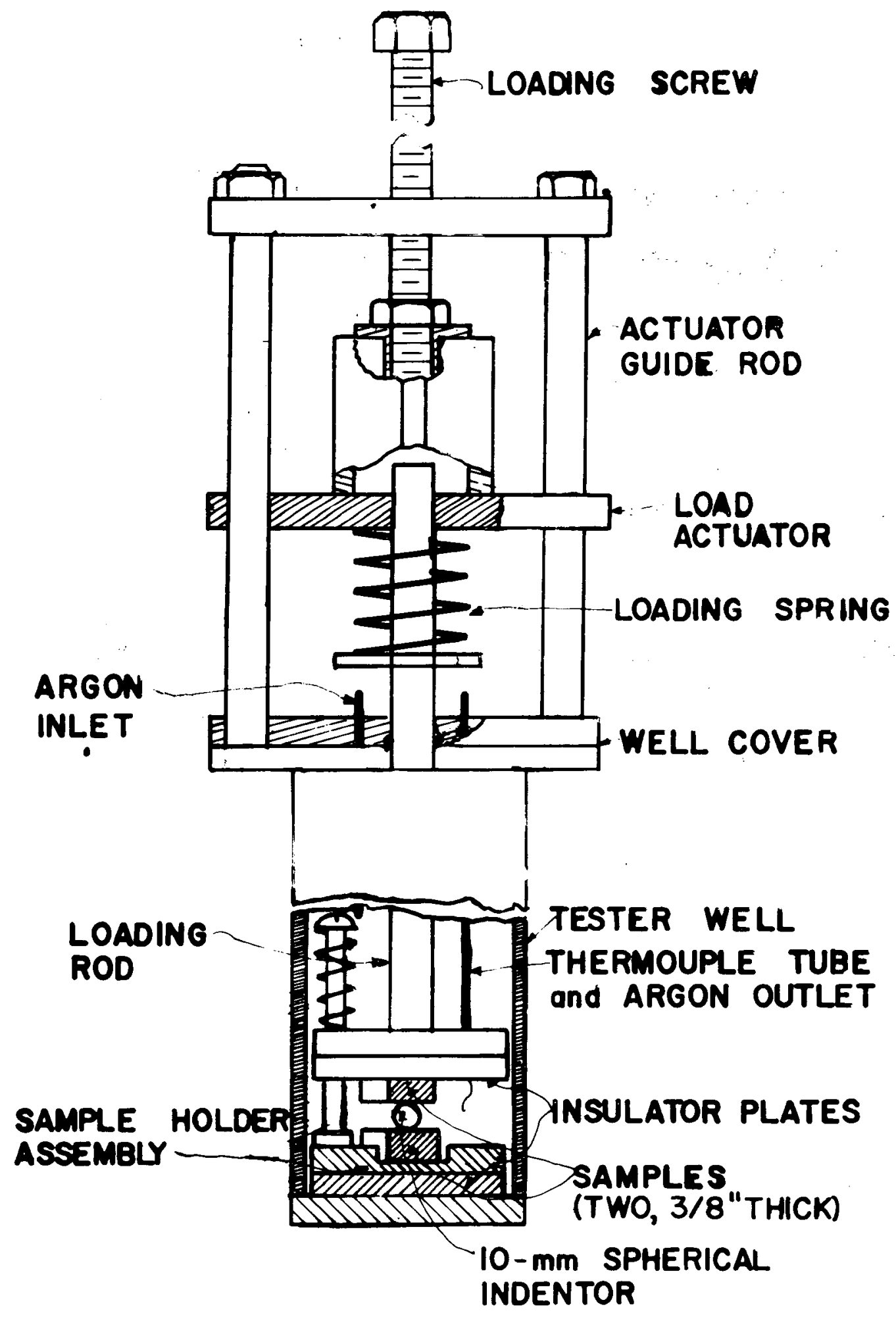

Figure 15. Design of a Spring-Loaded Tester for Prolonged Hot-Hardness Tests of Dilute Uranium Alloys. 


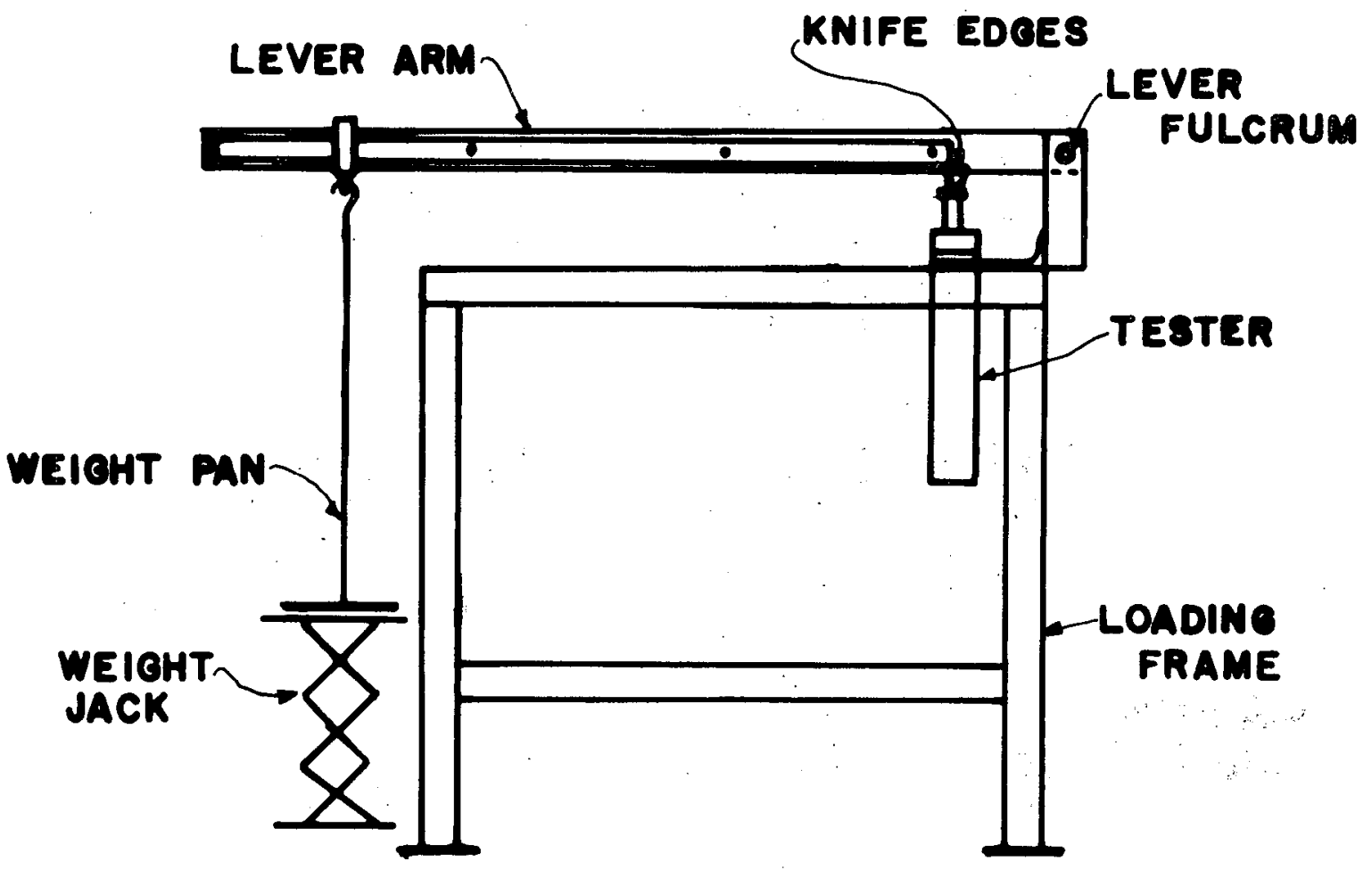

Figure 16. Design of a Lever-Loaded Tester for Prolonged Hot-Hardness Tests of Dilute Uranium Alloys. 


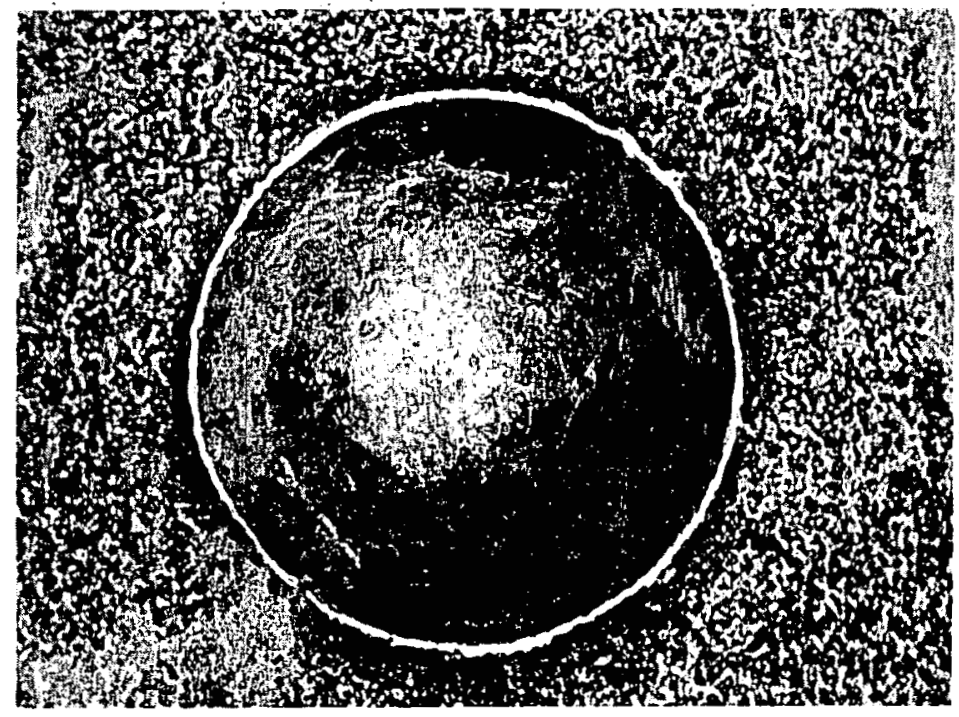

Figure 17. Appearance of a Representative Indentation Produced by the Prolonged Hot-Hardness Test. 


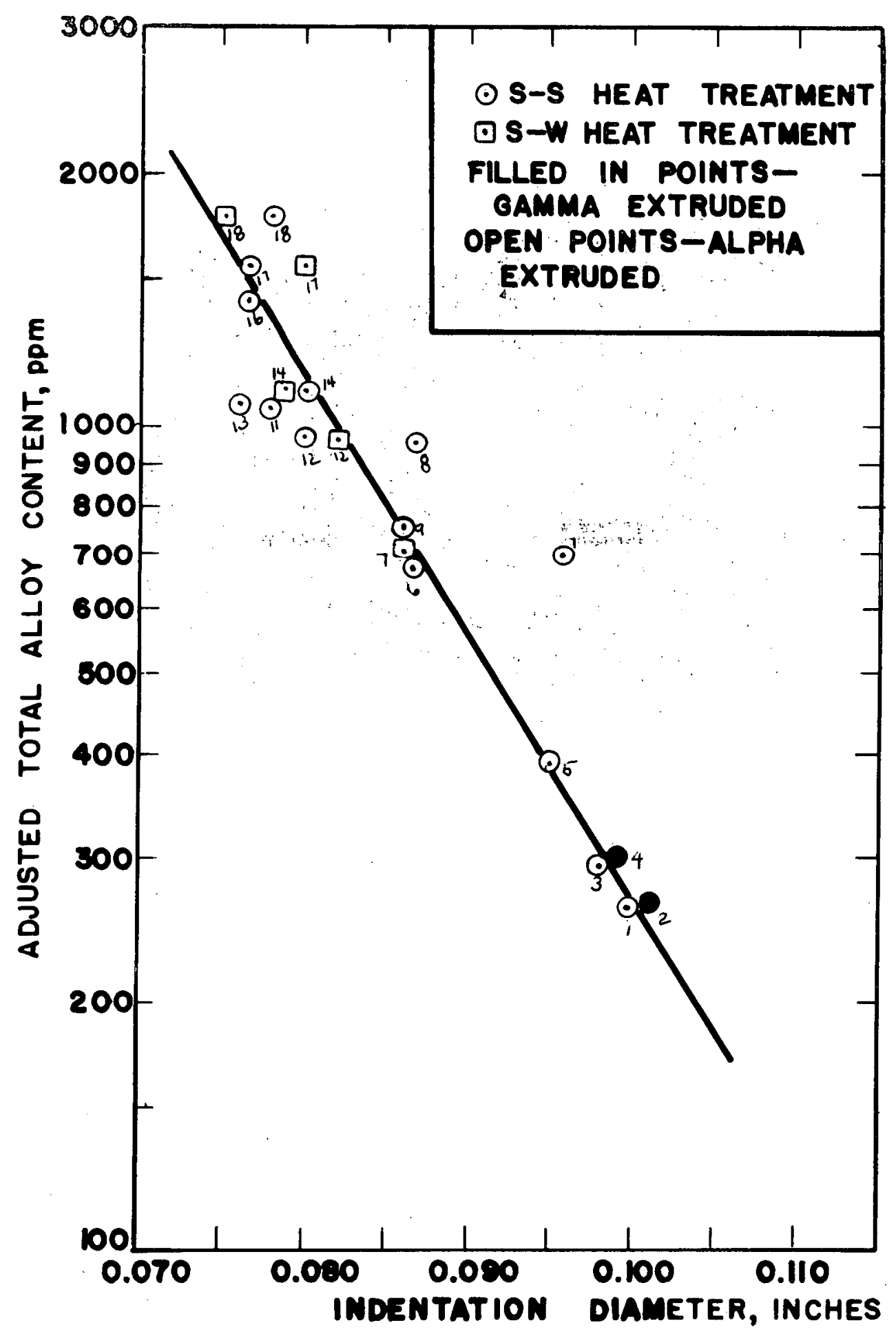

Figure 18. "Adjusted Total Alloy Content" for Severely Quenched Uranium Alloys Versus the Diameter of Indentation Resulting from the Prolonged Hot-Hardness Test. 


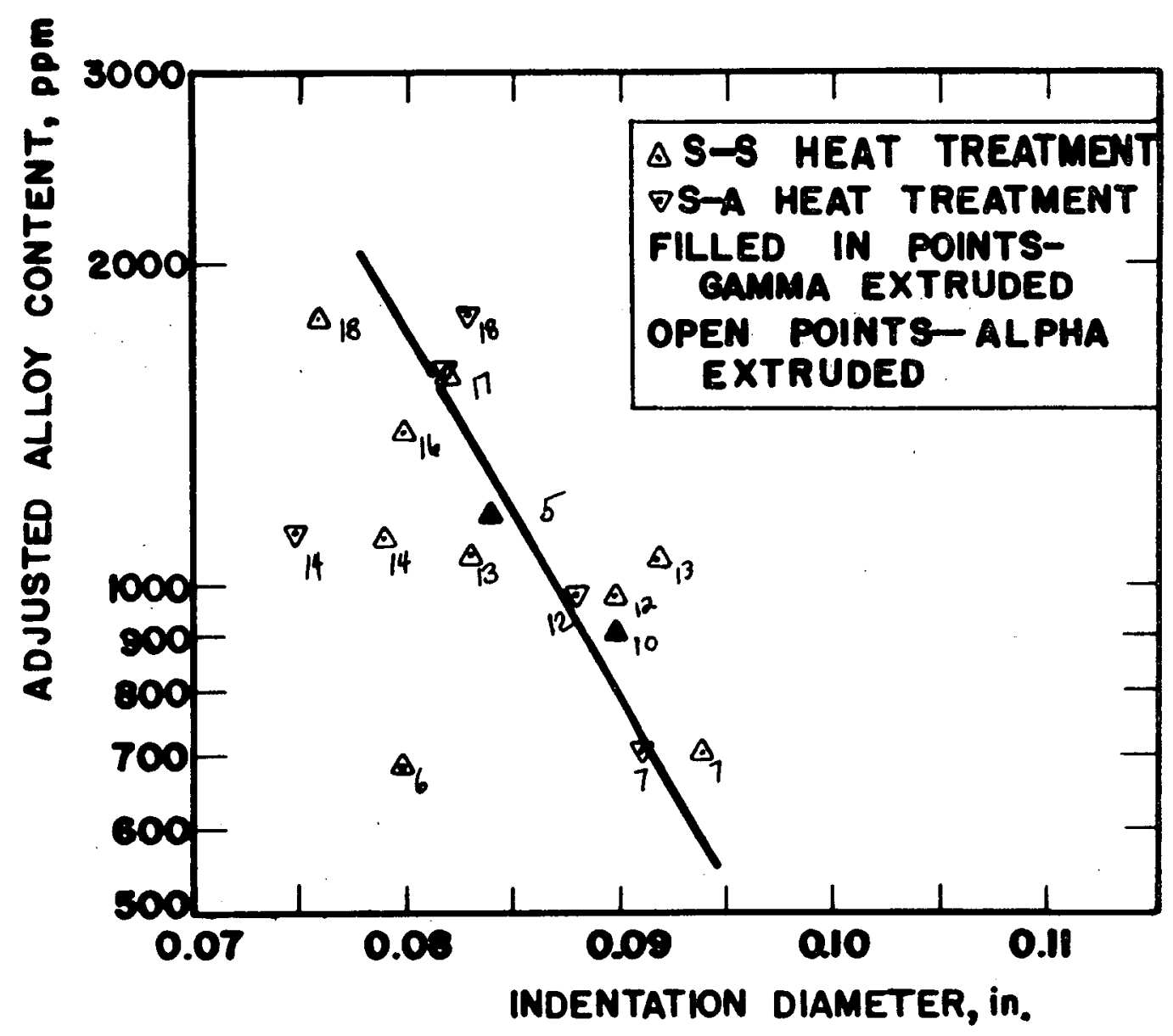

Figure 19. "Adjusted Total Alloy Content" for Slack-Quenched Uranium Alloys vs. the Diameter of Indentation Resulting from the Prolonged Hot Hardness Test. 


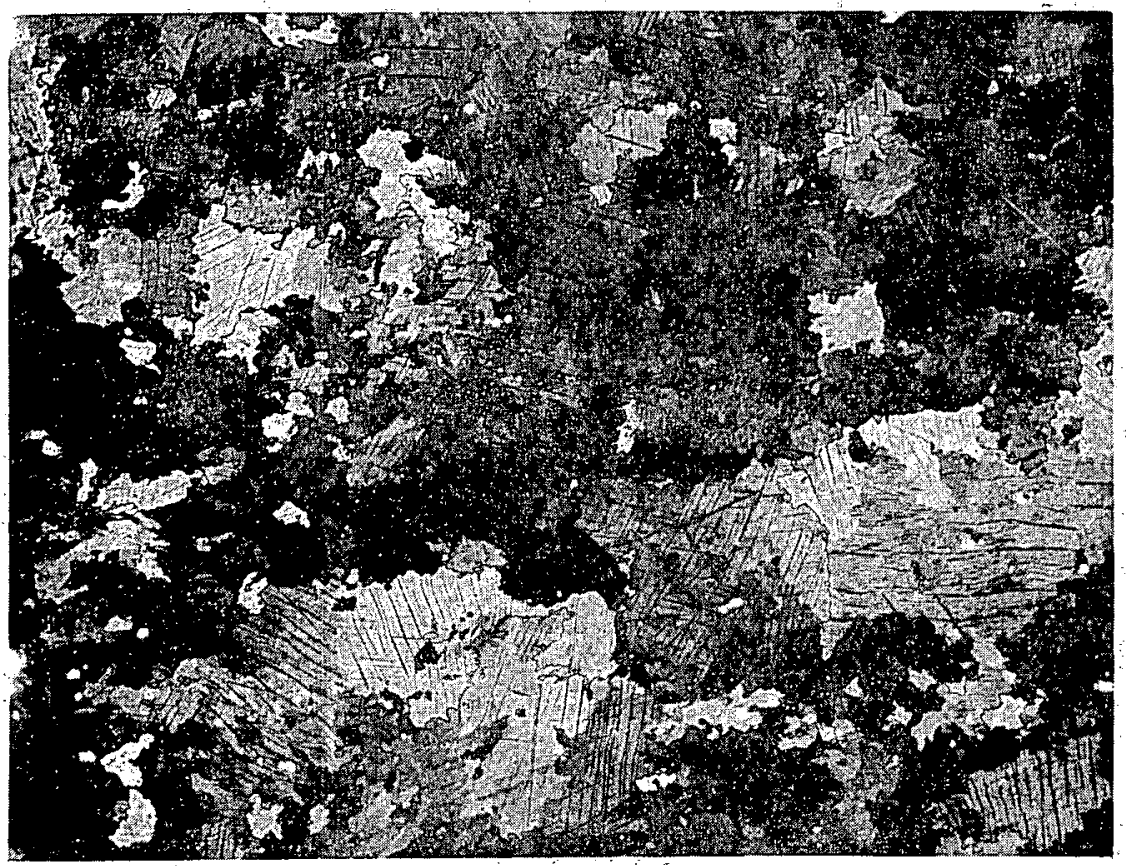

Figure 20. The Microstructure of the High-Molybdenum Alloy D-16 after a Beta Salt-Oil Heat Treatment. Fine precipitates are visible in the microstructure. Polarized light

illumination. 100X. 


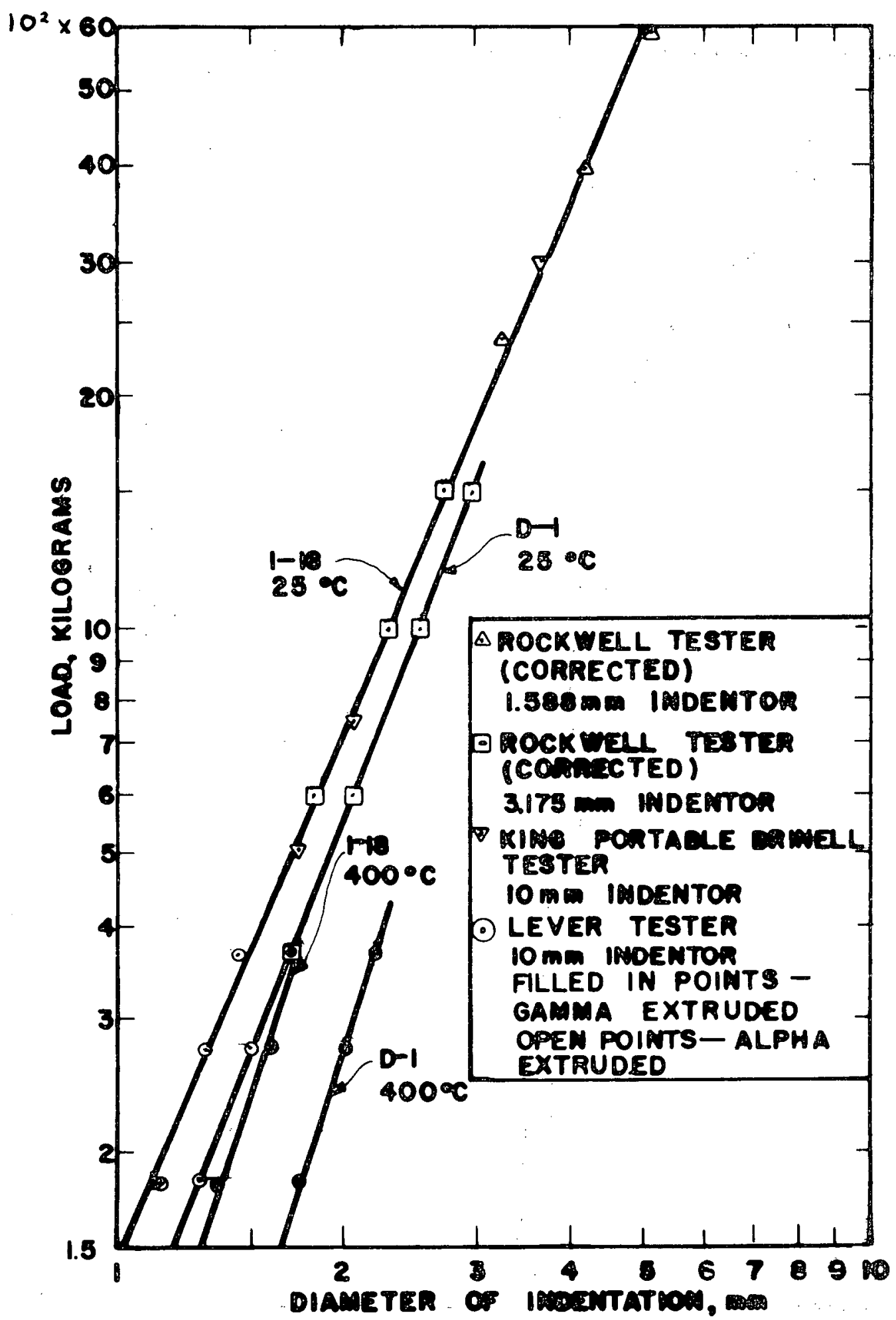

Figure 21. The Effect of Load on Indentation Diameter for Alloys D-1 and I-18; Tested at $25^{\circ} \mathrm{C}$ and $400^{\circ} \mathrm{C}$ with a $10-\mathrm{mm}$ Tungsten Carbide Ball. (Data from balls other than $10-\mathrm{mm}$ have been converted to equivalent values of load and indentation for a 10 -mm indentor.) 


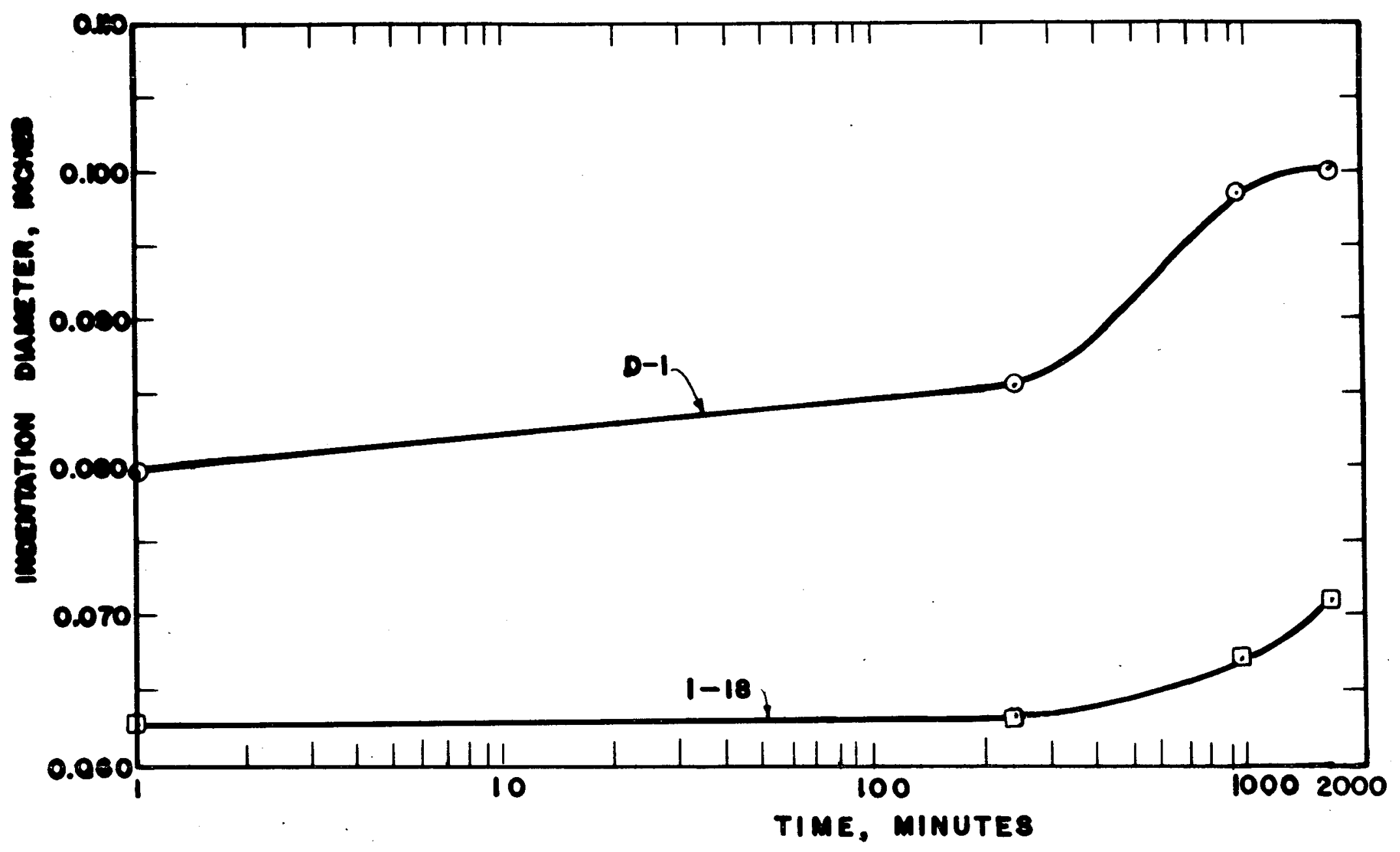

\&

Figure 22. Indentation Diameter versus Loading Time for Alloys D-1 and I-18. A 10 -mm tungsten ball and 600-pound load were used. 


\section{APPENDIX I}

\section{FUNCTIONS FOR CALCULATING TRUE STRESS AND TRUE STRAIN FROM LOAD ELONGATION DATA}

Engineer strain is defined as the change in length over an original gage length.

$$
e=\frac{L_{f}-L_{o}}{L_{o}}
$$

where $e=$ engineering strain

$L_{f}=$ final length

$I_{\infty}=$ original gage length

True strain is defined in terms of the instantaneous gage length.

$$
\epsilon=\int_{\mathrm{L}_{0}}^{\mathrm{L}_{\mathrm{f}}} \frac{\mathrm{dL}}{\mathrm{L}}=\ln \frac{\mathrm{L}_{\mathrm{f}}}{\mathrm{L}_{O}}
$$

Restating Equation 1

$$
\frac{L_{f}}{L_{o}}=e+1
$$

Thus, true strain may be related to engineering strain by Equation 4

$$
\epsilon=\ln (e+1)
$$

Engineering stress is defined in terms of load distributed over the original cross-sectional area.

$$
\sigma=\frac{P}{A_{0}}
$$

where $\sigma=$ engineering stress

$P=$ load

$A_{0}=$ original cross-sectional area

True stress is defined in terms of the instantaneous cross-sectional area.

$$
\sigma_{T}=\frac{P}{A_{i}}
$$

where $\varpi_{T}=$ true stress

$A_{1}=$ instantaneous cross section 
By assuming a constancy of volume relationship between cross sectional area and length obtained:

$$
\frac{A_{0}}{A_{i}}=\frac{L_{f}}{L_{o}}
$$

we may rewrite Equation (6) as

$$
\sigma_{T}=\frac{P}{A_{0}} \cdot \frac{L_{f}}{L_{O}}
$$

and from Equations (3) and (7), the true stress may be related to engineering strain by

$$
\sigma_{T}=\frac{P}{A_{0}}(e+1)
$$

